\title{
A theory of communication in political campaigns*
}

\author{
Philipp Denter \\ University of St.Gallen \\ philipp.denter@unisg.ch
}

Preliminary version

This version: August 2014. First draft: January 2012.

\begin{abstract}
In this paper I develop a formal theory of campaign communications. Voters have beliefs about the quality of candidates in the different policy issues and about the issues' relative importance. Candidates spend time or money (TV ads, public speeches, etc.) in an effort to influence voters' decisions at the ballot. Influence has two simultaneous effects: (i) it increases the quality of the policy in the issue as perceived by the voters through policy/competence advertising and (ii) it makes the issue more salient through issue priming, thereby increasing the issue's perceived importance. A strategy is an allocation of influence activities to the different issues or topics. I show conditions under which candidates' strategies converge or diverge, which issues - if any - will dominate the campaign, and under what conditions candidates are forced to focus on issues in which they are perceived to be weak. The results are often conflicting with previous theories of campaigning but are able to explain a set of anomalies.
\end{abstract}

Keywords: Multi issue campaign, campaign communication, policy advertising, issue priming JEL Codes: D01, D72, P16

${ }^{*}$ This paper is based on Chapter 2 of my Ph.D. dissertation. I would like to thank Stefan Bühler, Micael Castanheira, Subho Chowdhury, Hans Fricke, Marco Helm, Magnus Hoffmann, Martin Kolmar, John Morgan, Hendrik Rommeswinkel, Catherine Roux, Dana Sisak, Stergios Skaperdas, Rudi Stracke, seminar participants at UC Irvine, U. of St. Gallen, U. Mannheim, and U. Carlos III de Madrid as well as participants of the Economics Workshop in Tübingen, the Erasmus Political Economy Workshop in Rotterdam, the Tournaments, Contests, and Relative Performance Evaluation conference in Fresno, the EPCS meeting in Zürich, the Econometric Society NASM in Los Angeles, the APET meeting in Lisbon, and of the EEA/ESEM meeting in Gothenburg for insightful comments and suggestions. The kind hospitality of UC Irvine is gratefully acknowledged. I also gratefully acknowledge the financial support of the Swiss National Science Foundation through grant PBSGP1-135426. Of course, all errors are my own. 


\title{
1 Introduction
}

\author{
"[...] there is no shortage of explanations for why issue convergence \\ is such a rare commodity in American campaigns. Perhaps \\ surprisingly, though, there is a shortage of convincing \\ evidence that issue convergence really is a rare commodity." \\ Sigelman and Buell (2004)
}

During political campaigns, candidates for political office vie for voters' support at the ballot by giving public speeches, publishing TV ads, or by targeting different groups with tailored advertisement on the internet. In other words, they communicate their standpoints, policies, etc. and try to convince constituents of their quality as a political leader. Naturally, candidates differ significantly in some characteristics and are more similar in others. Some characteristics are important at a given time, while others are not. For example, during economic downturns, voters expect candidates to tell them how they plan to create jobs and the issue's importance is probably high. Similarly, after a terrorist attack, the issue of homeland security becomes increasingly important. A central question is now how candidates' characteristics and their relative importance together shape candidates' campaign communications. How should a candidate tailor his communication strategy optimally? When should a candidate focus on 'Job creation' and 'Homeland security' during his campaign, but put less emphasis on the issues 'Social security' and 'War in Afghanistan'? When should we expect candidates to follow similar communication strategies, and when is polarization a likely outcome? Which issues will dominate the campaign and which will be more or less neglected? In this paper I advance a theory of campaign communications that offers answers to these questions.

The theoretical campaigning literature so far is dominated by the seminal works of Petrocik (1996) and Riker (1996). Petrocik (1996) argued that each candidate owns certain issues, i.e. he is perceived to be more competent in this issue than her political opponent. Such an advantage in perceived competence has many different sources such as a party's history or a candidate's personal professional experience. For example, in the 2012 presidential campaign contest with Barack Obama, the Republican candidate Mitt Romney tried to connect his experience as a business leader to his competence in questions concerning the economy 1 Simon (2002) formal-

\footnotetext{
${ }^{1}$ For example, during the second debate with Barack Obama on October 16, 2012 he stated: "I want to make
} 
ized the ideas of Petrocik (1996) and came to similar conclusions as Riker (1996), who developed two principles of campaigning rhetoric: "When one side has an advantage on an issue, the other side ignores it; but when neither side has an advantage, both seek new and advantageous issues" (page 106). He named the former the dominance principle and the latter the dispersion principle. The prediction of the theory is hence that there is an extreme form of issue divergence in communication strategies because candidates will never address the same issues: Either the candidate with an advantage addresses an issue or, if their are no advantages, the issue will be neglected by all.

But how is the predictive power of these principles? Take a look at the 2008 campaign between Barack Obama and John McCain2 Take the issue 'Taxes': McCain spend some 21 percent of his budget for TV ads on that issue, which was almost matched by Obama, who also devoted more than 20 percent of his budget on that issue. Hence, this situation is best described by convergence, and the candidates converged also in other issues. Although there are also issues in which candidates diverged clearly, e.g. 'Health care' (14.2 vs. 2 percent), the predictions of the dominance and dispersion principles seem too strong. And in fact many empirical studies confirm this conclusion and the introductory quotation due to Sigelman and Buell (2004) is a nice résumé of the empirical literature so far. Still, there are no theoretical models that can account for these findings and explain the data.

In this paper I address this question and advance a formal theory of political communication in campaigns. At the heart of the analysis are two effects that simultaneously shape a voter's opinion: policy advertising and issue priming. The first posits that political influence / advertising is effective in the sense that is makes voters like candidates' advertised policies better or makes them believe a candidate is more competent in handling the respective issue. Advertising is persuasive and does not directly transmit information 3 The second effect, issue priming, posits that a commercial on health care reform or a speech about the current situa-

small businesses grow and thrive. I know how to make that happen. I spent my life in the private sector. I know why jobs come and why they go."

${ }^{2} \mathrm{I}$ calculated all numbers on TV ads using data from an online archive of the New York Times: http://elections.nytimes.com/2008/president/advertising/issues/1439-abortion.

${ }^{3}$ Many authors claim that persuasive advertising is most likely the most relevant form of campaigning, e.g. Mueller and Stratmann (1994) and Iaryczower and Mattozzi (2011). The assumption of persuasive advertising is very common in both political advertising and advertising on goods markets, see the two aforementioned papers or Iaryczower and Mattozzi (2013), Bühler and Halbheer (2012). Bagwell (2007) surveys the literature on advertising in general and contains also a chapter on persuasive advertising. 
tion in Iraq makes those issues salient and thereby shifts voters' attention towards these issues, thereby increasing their perceived importance. Priming can hence "alter the standards by which people evaluate election candidates" (Severin and Tankard, 1997) 4 For a discussion of possible psychological foundations for policy advertising and issue priming see Appendices A.1 and A.2. Campaign communication is modeled as a series of intertwined contests between the candidates. Voters hold beliefs about candidates' policy plans or competence in the issues and about issues' relative importance. Candidates give speeches or buy TV ads to influence voters. In an ad they address a given set of issues and elaborate on their own or their opponent's policy plans. This has two effect at the same time: talking about an issue primes the issue and hence increases its perceived importance. At the same time it makes voters like the policies of the candidate better (or the policies of the opponent less) 5 For reasons of exposition, I will refer to the two channels as 'issue priming' and 'policy advertising' throughout the paper, while keeping in mind that other interpretations-especially of policy advertising-are conceivable as well.

The main contributions of the paper are twofold. On the one hand it is the first paper to study the effects of issue priming and policy advertising simultaneous. This simple structure is sufficient to generate many novel testable predictions about candidates' communication strategies and those results are often at odds with the dominance and dispersion principle. On the other hand the paper can be seen as a methodological contribution. While the model is couched in the field of campaign communication, by its essence it is a model studying persuasive advertising when multiple characteristics matter and as such it can be used to study other interesting phenomena, such as advertising on goods markets, as well 6

The main results are the following:

- If a candidate has a comparative advantage in an issue, he will tend to target that issue with a higher intensity than his opponent. If there are no comparative advantages in some issues, candidates tend to put similar emphasis on these.

\footnotetext{
${ }^{4}$ Priming has a prominent role in the literature on campaign communications, e.g. Ivengar and Kinder (1987), Druckman, Jacobs, and Ostermeier (2004), Amorós and Puy (2013), or Aragonès, Castanheira, and Giani (2014).

${ }^{5}$ This may be so because in TV ads candidates address policy plans or because their perceived competence can be increased in public speeches.

${ }^{6}$ For example, according to Lancaster (1966) goods are simply a collection of characteristics that determine how much utility we receive from consumption. My model can then be used to study on which characteristics of a good different firms focus when creating marketing strategies. It might highlight another channel firms can use to differentiate products and thus to skim monopoly rents, for example.
} 
- A candidate might be forced by competitive pressure to pay the greatest attention to an issue in which he is disadvantaged, because voters deem him less competent than his opponent.

- From the point to view of the electorate, issues of secondary importance may dominate the campaign and thereby receive a high priority on the political agenda and possibly decide the election outcome.

A candidate has a comparative advantage in an issue if his policy in this issue is relatively more popular than a weighted average of the relative popularity of all his policies. If candidates have comparative advantages, it is beneficial to highlight one's advantage for two reasons. First, advertising a policy plan strengthens the advantage. Second, priming this issue draws attention to one's strength and away from one's weakness. This is also beneficial. While the advertising effect is also beneficial in issues in which a candidate does not have a comparative advantage, the priming effect is now detrimental. However, as long as the first effect dominates, the candidate will still publish some TV ads on that issue. Because of the additional costs (as which we can interpret the negative effect of priming), candidates publish more ads on their comparative advantages than on the other, unless the issue in which there is a disadvantage becomes very important. If this is the case, a marginal increase in perceived quality of one's policy platform in an issue has a relatively strong effect on a candidate's overall assessment, and hence in that issue the advertising effect dominates. To the contrary, in less important issues the priming effect is more important and there we should hence expect more divergence.

The model explains actual candidate behavior from the 2008 presidential campaign in the US nicely, e.g. the strong form of convergence in communication strategies in the issue 'Taxes' and other issues, and the strong form of divergence in issues like 'Health care', 'Immigration', and 'Economy'.

Related literature. Many scholars have directed their attention to the study of political campaigns. An often posed question is and was how candidates allocate their time and money during an electoral contest to different states and electoral districts, e.g. Snyder (1989), Klumpp and Polborn (2006), and Stromberg (2008), or to different forms of campaigning, e.g. Skaperdas and Grofman (1995). In contrast to these papers, in the current paper the focus is on 
candidates' communication strategies during a campaign, that is how different issues are being addressed.

Petrocik (1996) argued that candidates and parties own certain issues. He purports that candidates will focus in their campaign communication on issues that they own, and neglect others. Simon (2002) formalized this idea. A similar result was established by Riker (1996) and subsequent authors like Amorós and Puy (2013). The common predictions of these models is an extreme form of divergence in communication strategies: A candidate never addresses an issue in which the opponent has an advantage and if nobody has an advantage, the issue remains untouched 7 However, empirical scholarship tends to reject this prediction, see for example Bélanger and Meguid (2008), Damore (2004, 2005), Kaplan. Park. and Ridout (2006), Green and Hobolt (2008), Petrocik, Benoit, and Hansen (2003), or Sigelman and Buell (2004). In fact, candidates often devote significant time and resources to issues that are owned by their opponent and also issues that are not owned by a candidate receive ample attention. In this paper I develop an alternative theory that can account for these findings.

Recently, some authors have developed theories that aim to explain how issue ownership is determined. For example, Krasa and Polborn (2010b) develop a formal model in which candidates differ in their productivity to produce certain public goods and show how this leads to policy divergence. Aragonès, Castanheira, and Giani (2014) model a two stage competition between candidates with issue specific abilities who can prime issues in the campaign, and study the repercussions of campaigning behavior for investment in platform quality. In contrast to these papers, the focus here is not the emergence of issue ownership and policy platforms, but the consequences of issue ownership for campaigning.

The paper also relates to a literature studying models in which candidates have different characteristics, for example Groseclose (2001), Jensen (2012) or a series of papers by Krasa and Polborn (2012, 2010a,b). In all these papers, the focus is on sorting out how certain differences between candidates influences policy choices in equilibrium. Unlike these papers, the current paper is concerned with the implications of candidates' different characteristics for campaign communication strategies.

The model can be interpreted as a variant of a Colonel Blotto game, e.g. Shubik and Weber

\footnotetext{
${ }^{7}$ In the paper by Amorós and Puy (2013) the result that convergence is not possible only holds when the focus is on pure strategy equilibria. If those fail to exist, partial convergence in mixed strategies may happen.
} 
(1981). These games represent situations in which combatants fight on multiple battlefields, and the question of interest is how to allocate forces to the different battlefields. Roberson (2006) described equilibrium payoffs for a wide range of Blotto games. Other authors working on Blotto-like games are Powell (2007), Chowdhury, Kovenock, and Sheremeta (2013), or Kovenock and Roberson (2010, 2012). The distinctive feature of the current paper is the endogeneity of the value of a battlefield (an issue), which is assumed fixed in all these papers.

\section{An introductory example}

In this section I lay down the principles of the more general model later on. Suppose there are just two issues $i=A, B$ and two candidates $k=1,2$. Candidate 1's perceived competence in issue $i$ is $c_{1}^{i}$, where, without loss of generality $1 \geq c_{1}^{i} \geq 0$ and $c_{1}^{i}+c_{2}^{i}=1$. This assumption implies we can drop the candidate index and just use $c^{i}$ for candidate 1 's competence. The issues' weights are $w$ and $1-w$ respectively. The representative voter evaluates a candidate by the weighted average quality, that is he receives utility from candidate 1 equal to

$$
u(1)=c^{A} \cdot w+c^{B} \cdot(1-w)
$$

and $u(2)=1-u(1)$. Voting is probabilistic and these utilities coincide with the probabilities of being elected. Candidates can buy TV advertising with the aim to convince voters. For simplicity, at this point I assume this is possible only for issue $A$ and that each candidate has the option either to buy TV advertising $x$ (at no costs) or buy no TV advertising. This assumption will be relaxed later. Advertising has the effect of increasing the own perceived competence and it primes the issue as well. Hence, suppose $c^{i}(x, 0)>c^{i}(x, x)=c^{i}(0,0)>c^{i}(0, x)$ and $w(2 x)>w(x)>w(0)$. The resulting game between candidates is a simple 2 player 2 actions

game. Now suppose $c^{B}>c^{A}$, that is candidate 1 is perceived more competent in issue $B$ than $A$. What will be the equilibrium? In particular, can a (strict) convergence Nash equilibrium exist in which both candidates choose to advertise? This is the case whenever the following two conditions simultaneously hold:

$$
\begin{aligned}
c^{A}(x, x) w(2 x)-c^{A}(0, x) w(x) & >c^{B}[w(2 x)-w(x)] \\
\left(1-c^{A}(x, x)\right) w(2 x)-\left(1-c^{A}(0, x)\right) w(x) & >\left(1-c^{B}\right)[w(2 x)-w(x)]
\end{aligned}
$$


Note that this generally holds when $w(2 x)-w(x)$ approaches zero and that it cannot hold if $c^{A}(x, x)-c^{A}(0, x)$ approaches zero. These are the two effect determining incentives. To the first I will refer as issue priming henceforth. It describes how changing the salience of an issue alters a candidates evaluation. To the second I will refer as policy advertising and it describes how changes in perceived competence alter a candidate's evaluation. Without policy advertising, a strict convergence equilibrium cannot exist. However, without issue priming there cannot be a strict divergence equilibrium either 8 In general, if policy advertising is sufficiently strong relative to issue priming, a strict convergence equilibrium exists. Note that for divergence to exist in equilibrium it is not important that a candidates is dominant in an issue, as predicted by Riker's principle, but that there are comparative advantages.

Note that I assumed nothing but $c^{B}(0,0)>c^{A}(0,0)$. Whether or not candidate 1 is stronger than his opponent candidate 2 in any issue does not play a role. This is a general result of the model and was also discovered by Amorós and Puy (2013) for the case of a two issue pure priming campaign.

\section{The full model}

Two politicians $j \in\{1,2\}$ compete in a campaign for political office by exerting effort. While effort can mean many different things, for specificity I will refer to effort in the following as publishing or buying TV advertising. There is a measure-one continuum of voters, indexed by $v$. Voters care about $n$ policy issues, $i \in\{1,2, \ldots, n\}$. They assign to each candidate a relative competence belief $\theta_{v, j}^{i} \in[0,1]$, where, without loss of generality, relative competence is defined in a way such that $\theta_{v, 1}^{i}+\theta_{v, 2}^{i}=1$. It is useful to define $\theta_{v, 1}^{i} \equiv \theta_{v}^{i}$ and $\theta_{v, 2}^{i} \equiv 1-\theta_{v}^{i}$ and work with this in the following. Denote by $\theta_{v}=\left\{\theta_{v}^{1}, \theta_{v}^{2}, \ldots, \theta_{v}^{n}\right\}$ the vector of competence beliefs held by voter $v$.

To assess the overall quality of a politician, voters assign a weight $\omega_{v}^{i} \in[0,1]$ to issue $i$ where $\sum_{i=1}^{n} \omega^{i}=1$. Denote by $\omega_{v}=\left\{\omega_{v}^{1}, \omega_{v}^{2}, \ldots, \omega_{v}^{n}\right\}$ the vector of ex-ante (that is before campaigning starts) importance weights held by voter $v$. Voters have weighted-issue preferences as in Krasa and Polborn (2010a) or Bélanger and Meguid (2008) and a voter assumes to receive

\footnotetext{
${ }^{8}$ I restrict myself to strict Nash equilibria in this example to exclude the case when both effects are zero.
} 
utility $u_{v, k}\left(\theta_{v}, \omega_{v}\right)$ if candidate $j$ gets elected, where

$$
\begin{aligned}
& u_{v, 1}\left(\theta_{v}, \omega_{v}\right)=\sum_{i=1}^{n} \theta_{v}^{i} \omega_{v}^{i}, \\
& u_{v, 2}\left(\theta_{v}, \omega_{v}\right)=\sum_{i=1}^{n}\left(1-\theta_{v}^{i}\right) \omega_{v}^{i} .
\end{aligned}
$$

Hence, when $u_{v, 1}>\frac{1}{2}$ voter $v$ prefers 1 over 2 , and vice versa if $u_{v, 1}<\frac{1}{2}$.

Voters' beliefs about candidates' relative competence in issue $i$ are distributed on $\Theta^{i}=$ $\left[\underline{\theta}^{i}, \bar{\theta}^{i}\right] \subseteq[0,1]$ with distribution $\mathcal{C}^{i}\left(\theta_{v}^{i}\right)$. Similarly, the issue importance beliefs are distributed on $\Omega^{i}=\left[\underline{\omega}^{i}, \bar{\omega}^{i}\right] \subseteq[0,1]$ with distribution $\mathcal{I}^{i}\left(\omega_{v}^{i}\right)$. Hence, voters' competence belief space is $\Theta=\Theta^{1} \times \Theta^{2} \times \cdots \times \Theta^{n}$ and voters' importance belief space is $\Omega=\Omega^{1} \times \Omega^{2} \times \cdots \times \Omega^{n}$. Accordingly, every voter $v$ is completely described by $s_{v} \in \mathcal{S} \equiv \Theta \times \Omega$. Beliefs are independent draws from $\mathcal{S}$.

Having described how voters assess candidates before the campaign starts, I now describe the process of campaigning. Candidates can buy TV advertising in an effort to sway voters. Advertising may have an influence on voters' evaluation of candidates for different reasons. First, if voters dislike uncertainty, informative TV advertising can help reduce uncertainty about policies and voters like that. Alternatively, it may be the case that different policies can be appropriate in different states of the world. For example, a fiscal stimulus to the economy may seem appropriate during economic downturns, but not quite as appropriate when the economy is roaring. TV advertising can then be used to try to convince voters that in the current state of the world the chosen policy is appropriate 9 I will refer to this function of campaigning as policy advertising and assume advertising is effective. A candidate's advertising expenditures being effective means that the assessment of a candidate's competence is non-decreasing (in expectation) in the number of published TV ads, $x_{k}^{i}$. Denote by $\mathbf{x}=\left\{x_{1}^{1}, x_{1}^{2}, \ldots, x_{1}^{n}, x_{2}^{1}, x_{2}^{2}, \ldots, x_{2}^{n}\right\}$ the vector of spending from both candidates and denote voter $v$ 's after-campaigning assessment of candidates' relative competence by $c_{v, 1}^{i} \equiv c_{v}^{i}$ and $c_{v, 2}^{i} \equiv 1-c_{v}^{i}$, I assume the following campaigning technology:

$$
c_{v}^{i}(\mathbf{x} ; s)=\frac{\theta_{v}^{i} f\left(x_{1}^{i}\right)}{\theta_{v}^{i} f\left(x_{1}^{i}\right)+\left(1-\theta_{v}^{i}\right) f\left(x_{2}^{i}\right)},
$$

\footnotetext{
${ }^{9}$ I will not discuss in detail what exactly advertising does, but assume it to be effective. That this assumption is not very strict has been shown repeatedly in empirical work, e.g. Erikson and Palfrey (2000).
} 
$f(x)>0$ measures the impact of publishing TV advertising and is an increasing and concave function function. The (relative) competence beliefs also determines the relative effectiveness of spending. If both candidates spend an equal amount on TV advertising, $c_{v}^{i}\left(x, x, \theta_{v}^{i}\right)=\theta_{v}^{i}$. This functional form has been employed frequently to model campaigning, e.g. Snyder (1989), Skaperdas and Grofman (1995), and Klumpp and Polborn (2006) 10

I make the following assumptions about the function $f($.$) :$

Assumption 1. $f(x)$ is $\mathcal{C}^{2}, f(0)>0, f^{\prime}(x)>0$, and $f^{\prime \prime}(x)<2 f(1) f^{\prime}(x)^{2} \forall x \in[0,1]$.

Part 1 means that even if a candidate does not spend anything in the campaign his perceived competence remains positive. A direct implication is that perceived competence is a continuous function of candidates' efforts and voters' pre-campaigning beliefs. Part 2 reflects that advertising is effective. Part 3 restricts the second derivative of $f(x)$ and allows for both increasing as well as decreasing returns of advertising. The assumption is somewhat more restrictive than log-concavity. An example for a function fulfilling Assumption 1 is $f(x)=\left(\kappa_{1}+\kappa_{2} x\right)^{a}$ for some $\kappa_{1}, \kappa_{2}>0$ and $1>a>0$.

While policy advertising is one purpose of TV advertising, it is not the only one. Advertising also primes an issue. The more ads candidates publish on issue $i$, the more salient the issue becomes and the more attention will be directed towards this issue. As a consequence, the issue's relative importance increases (and the importance of all other issues decreases). This issue priming effect has been studied extensively and lies at the heart of most campaigning models, e.g. Amorós and Puy (2013) and Aragonès, Castanheira, and Giani (2014) 11 With $\omega_{v}^{i}$ being a voter's importance belief of issue $i$, priming leads to a reassessment of issues' relative importance. In particular, denoting by $w_{v}^{i}(\mathbf{x} ; s)$ the after-campaigning belief of voter $v$, I assume the following functional form:

$$
w_{v}^{i}(\mathbf{x} ; s)=\frac{\omega_{v}^{i} g\left(x_{1}^{i}+x_{2}^{i}\right)}{\sum_{j=1}^{n} \omega_{v}^{j} g\left(x_{1}^{j}+x_{2}^{j}\right)}
$$

The priming technology closely resembles the advertising technology, but may of course be different. I make the following assumptions regarding $g(x)$ :

\footnotetext{
${ }^{10}$ Skaperdas and Vaidya (2012) derive this functional form as a technology of persuasion / advertising based on a Bayesian learning model.

${ }^{11}$ See Appendix for a short discussion of the psychological foundations.
} 
Assumption 2. $g(x)$ is $\mathcal{C}^{2}, g(0)>0$, and $g^{\prime}(x)>0$.

The assumptions have a similar interpretation as Assumption 1, The assumption regarding the third derivative is to ensure a quasi-concave and hence well-behaved problem 12 An example function fulfilling Assumption 2 is $g(x)=\left(\kappa_{3}+\kappa_{4} x\right)^{b}$ for some $\kappa_{3}, \kappa_{4}>0$ and $1>b>0$. An intuitive property of this technology is that whenever two issues receive an identical amount of attention, their relative weights remain unchanged.

Given the above and the structure of preferences, voters' assessment of candidates after campaigning is

$$
\begin{aligned}
& U_{v, 1}(\mathbf{x} ; s)=\sum_{i=1}^{n} c_{v}^{i}(\mathbf{x} ; s) w_{v}^{i}(\mathbf{x} ; s) \\
& U_{v, 2}(\mathbf{x} ; s)=\sum_{i=1}^{n}\left(1-c_{v}^{i}(\mathbf{x} ; s)\right) w_{v}^{i}(\mathbf{x} ; s) .
\end{aligned}
$$

Voting is probabilistic (e.g. Lindbeck and Weibull (1987) or Kamada and Kojima (2013)) and for simplicity the probability that a voter cast her ballot for a candidate equals $U_{v, j} 13$ Candidates maximize the probability of being elected subject to the costs of campaigning, with constant marginal costs $\gamma>0$ for both. I will maintain this assumption for the rest of the paper. However, it can be shown that qualitatively identical results apply if candidates have a fixed campaigning budget instead.

We can write candidates' respective maximization problem as

$$
\begin{aligned}
\max _{\mathbf{x}_{1}} \pi_{1}(\mathbf{x} ; s) & =\int \ldots \int_{s} \sum_{i=1}^{n} c_{v}^{i}(\mathbf{x} ; s) w_{v}^{i}(\mathbf{x} ; s) \prod_{i=1}^{n} d \mathcal{C}^{i}\left(\theta_{v}^{i}\right) d \mathcal{I}^{i}\left(\omega_{v}^{i}\right)-\gamma \sum_{i=1}^{n} x_{1}^{i} \\
& =E_{\mathcal{S}}\left[\sum_{i=1}^{n} c_{v}^{i}(\mathbf{x} ; s) w_{v}^{i}(\mathbf{x} ; s)\right]-\gamma \sum_{i=1}^{n} x_{1}^{i} \\
\max _{\mathbf{x}_{2}} \pi_{2}(\mathbf{x} ; s) & =\int \ldots \int_{s} \sum_{i=1}^{n}\left(1-c_{v}^{i}(\mathbf{x} ; s)\right) w_{v}^{i}(\mathbf{x} ; s) \prod_{i=1}^{n} d \mathcal{C}^{i}\left(\theta_{v}^{i}\right) d \mathcal{I}^{i}\left(\omega_{v}^{i}\right)-\gamma \sum_{i=1}^{n} x_{2}^{i} \\
& =E_{\mathcal{S}}\left[\sum_{i=1}^{n}\left(1-c_{v}^{i}(\mathbf{x} ; s)\right) w_{v}^{i}(\mathbf{x} ; s)\right]-\gamma \sum_{i=1}^{n} x_{2}^{i}
\end{aligned}
$$

A rule that determines how candidates allocate resources to the different issues-given the electorates' beliefs-is called a communication strategy. The main goal is to identify conditions under which communication strategies converge or diverge, which issues will be in the focus

\footnotetext{
${ }^{12}$ An alternative assumption guaranteeing a nicely behaved problem, that would allow us to dispense with Assumptions 2.3-2.5, is $0<g^{\prime}(x)<\alpha_{1}$ and $\left|g^{\prime \prime}(x)\right|<\alpha_{2}$ for appropriately chosen $\alpha_{1}$ and $\alpha_{2}$.

${ }^{13}$ Any function $\operatorname{Pr}\left[b_{v}=j\right]=\zeta\left(U_{v, j}\right)$, where $\zeta^{\prime}()>$.0 and $\zeta\left(U_{v, 1}\right)+\zeta\left(U_{v, 2}\right)=1$, would yield qualitatively identical outcomes.
} 
of candidates, and which issue, if any, will be dominating in the campaign. The equilibrium concept I employ is Nash equilibrium.

For the remainder of the paper I will assume an interior pure strategy equilibrium exists. Conditions that guarantee that, based on Assumptions 1 and 2, are discussed in Appendix B.1, In Appendix ?? I also discuss equilibria in which some subset of issues is muted/neglected by one or both candidates.

\section{Communication strategies}

\subsection{Individual strategies: convergence or divergence?}

We have seen in the introductory example that comparative advantages rather than absolute advantages determine whether candidates converge or diverge on an issue. For the more general case we also need a more general definition:

Definition 1 (Comparative Advantage). Candidate 1 has an after-campaigning comparative advantage in issue $i$ if

$$
\sigma^{i}:=E_{\mathcal{S}}\left[c_{v}^{i}(\mathbf{x} ; s)\right]-E_{\mathcal{S}}\left[\sum_{j=1}^{n} c_{v}^{j}(\mathbf{x} ; s) w_{v}^{j}(\mathbf{x} ; s)\right]>0
$$

If $\sigma^{i}<0$, candidate 2 has a comparative advantage in $i$. If $\sigma^{i}=0$, no candidate has a comparative advantage in that issue.

This definition has some intuitive appeal because a candidate has a comparative advantage in an issue $i$ exactly when his perceived competence in that issue is greater than his average evaluation as seen by the constituency. For example, in the case of three issues $i=\{1,2,3\}$ which all have equal weights $w^{i}=1 / 3$, and candidate 1 's perceived competence in the issues is given by $c_{1}=\left\{c_{1}^{1}, c_{1}^{2}, c_{1}^{3}\right\}=\left\{\frac{3}{6}, \frac{4}{6}, \frac{5}{6}\right\}$, such that candidate 1 is weakly better than his opponent

in all issues, we get $\sigma^{1}=-\frac{1}{6}, \sigma^{2}=0$, and $\sigma^{3}=\frac{1}{6}$ : Candidate 1 has a comparative advantage in issue 3,2 has a comparative advantage in issue 1, and no candidate has a comparative advantage in issue 2. Note also that the definition of comparative advantage boils down to what we have seen in the introductory example if there are two issues only. Moreover, unlike in previous papers on campaign communication, comparative advantages are not based solely on 
competence measures but issues' weights play an important role as well. Hence, according to this definition, comparative advantages may change when issue weights are altered. The only two issues in which comparative advantages are invariant with respect to such changes are the two candidates respective best issues. Independent of issue weights, a candidate's best issue is always better than the average. Hence, whenever candidates assigned competence levels differ between issues, each of the two has a comparative advantage in his own best (where the $c^{i}$ is highest). This definition of comparative advantage is therefore different from the one in Amorós and Puy (2013) and Aragonès. Castanheira, and Giani (2014), which only takes into account information about relative competence levels. Pre-campaigning comparative advantages are defined in a similar way and I use $\tilde{\sigma}^{i}$ instead of $\sigma^{i}$.

In an interior pure strategy Nash equilibrium behavior can be determined by appealing to the first order conditions (FOCs) of the candidates. Consider the FOCs of both candidates in issue $i$ :

$$
\begin{aligned}
\frac{\partial \pi_{1}(\mathbf{x} ; \mathcal{S})}{\partial x_{1}^{i}} & =E_{\mathcal{S}}\left[\frac{\partial c_{v}^{i}(\mathbf{x} ; \mathcal{S})}{\partial x_{1}^{i}} w_{v}^{i}(\mathbf{x} ; \mathcal{S})+\sum_{j=1}^{n} c_{v}^{j}(\mathbf{x} ; \mathcal{S}) \frac{\partial w_{v}^{j}(\mathbf{x} ; \mathcal{S})}{\partial x_{1}^{i}}\right]-\gamma \stackrel{!}{=} 0 \\
\frac{\partial \pi_{2}(\mathbf{x} ; \mathcal{S})}{\partial x_{2}^{i}} & =E_{\mathcal{S}}\left[-\frac{\partial c_{v}^{i}(\mathbf{x} ; \mathcal{S})}{\partial x_{2}^{i}} w_{v}^{i}(\mathbf{x} ; \mathcal{S})+\sum_{j=1}^{n}\left(1-c_{v}^{j}(\mathbf{x} ; \mathcal{S})\right) \frac{\partial w_{v}^{j}(\mathbf{x} ; \mathcal{S})}{\partial x_{2}^{i}}\right]-\gamma \stackrel{!}{=} 0
\end{aligned}
$$

To see how this may relate to comparative advantages let $w^{i}=1-\sum_{j \neq i} w^{j}$, which is always possible because $\sum_{i=1}^{n} w^{i}=1$. We can rewrite the FOCs now in the following way:

$$
\begin{aligned}
& \frac{\partial \pi_{1}(\mathbf{x} ; s)}{\partial x_{1}^{i}}=E_{\mathcal{S}}\left[\frac{\partial c_{v}^{i}(\mathbf{x} ; s)}{\partial x_{1}^{i}} w_{v}^{i}(\mathbf{x} ; s)+\sum_{j \neq i}\left(c_{v}^{j}(\mathbf{x} ; s)-c_{v}^{i}(\mathbf{x} ; s)\right) \frac{\partial w_{v}^{j}(\mathbf{x} ; s)}{\partial x_{1}^{i}}\right]-\gamma \stackrel{!}{=} 0 \\
& \frac{\partial \pi_{2}(\mathbf{x} ; s)}{\partial x_{2}^{i}}=E_{\mathcal{S}}\left[-\frac{\partial c_{v}^{i}(\mathbf{x} ; s)}{\partial x_{2}^{i}} w_{v}^{i}(\mathbf{x} ; s)-\sum_{j \neq i}\left(c_{v}^{j}(\mathbf{x} ; s)-c_{v}^{i}(\mathbf{x} ; s)\right) \frac{\partial w_{v}^{j}(\mathbf{x} ; s)}{\partial x_{1}^{i}}\right]-\gamma \stackrel{!}{=} 0
\end{aligned}
$$

The term in brackets shows us already that for each issue a comparison of that issue and all others determines incentives. At the same time, the term in brackets has a positive sign for candidate 1 and a negative for candidate 2. Hence, whenever this term is non-zero it drives a wedge between incentives of candidates. Closer inspection reveals that it is the equivalent of the issue priming effect discussed earlier: It is the sum of pairwise issue comparisons weighted by the changes in issues' importance. Note that the change in issues importance is negative in all cases because we defined $w^{i}$ as the residual of all other weights. Hence, whenever candidate 1 is 

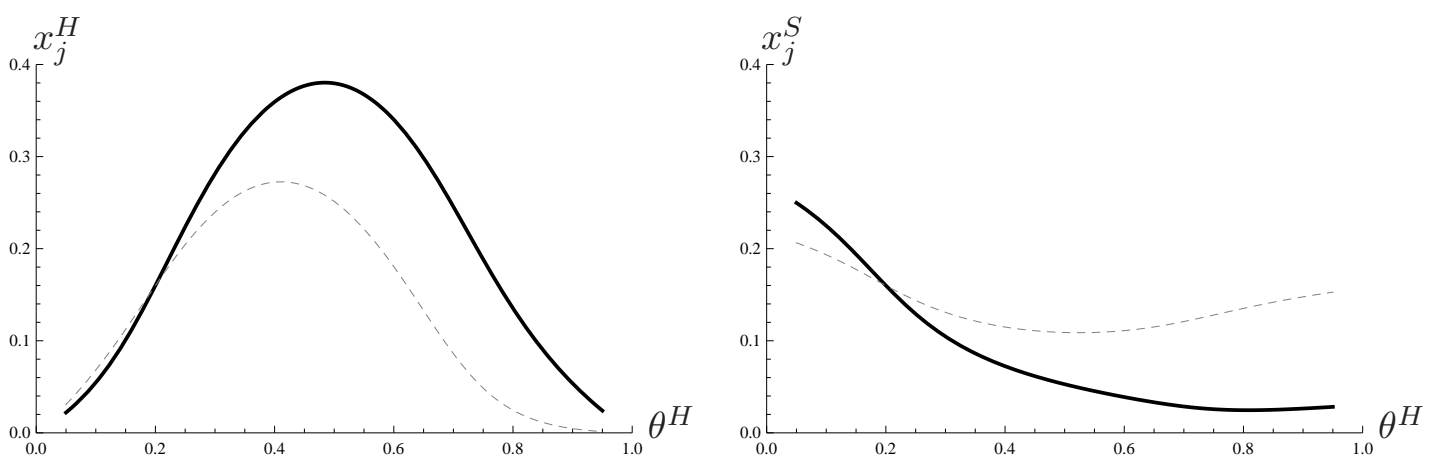

Figure 1: Equilibrium spending of 1 (solid line) and 2 (dashed line) in the different issues as $\theta^{H}$ varies, where $\bar{f}(x)=\frac{1}{200}+x, \bar{g}(x)=\frac{1}{2}+x, \theta^{S}=\frac{1}{5}, \omega=\frac{1}{2}$, and $\gamma=\frac{1}{2}$. It is easy to see that when 1 has a comparative advantage in $H, \theta^{H}>\frac{1}{5}$, he publishes more ads than 2 on $H$ (left panel) and less on $S$ (right panel). Since $\omega=\frac{1}{2}$, at $\theta^{H}=\theta^{S^{5}}=\frac{1}{5}$, there is complete convergence.

perceived more competent in issue $i$ than in another one, spending incentives increase, whereas the opposite holds when he is perceived worse in $i$. The average effect determines overall incentives for candidate 1 and hence also for candidate 2. Formally, we find the following:

Proposition 1. The candidate with the after-campaigning comparative advantage in issue $i$ spends more on $i$ in the campaign. If no candidate has a comparative advantage, they will both spend the same on that issue.

The proposition generalizes the result we have seen in the introductory example. What are the main takeaways? First, we see that in a quite general setting it is indeed comparative advantages that determine whether there is convergence or divergence in an issue. In contrast to earlier papers studying campaigning this is the case in interior equilibria and hence the model is able to explain imperfect divergence. In fact, if there are no comparative advantages the model predicts perfect convergence:

Corollary 1. When there are no ex-ante comparative advantages, $\tilde{\sigma}^{i}=0 \forall i$, there always exists a completely symmetric equilibrium in which both candidates advertise each issue with identical intensity, $x_{1}^{i}=x_{2}^{i} \forall i$. Consequently, there are no after-campaigning comparative advantages as well, $\sigma^{i}=0 \forall i$.

This result is a direct corollary of Proposition 1. In that situation there are neither ex-ante comparative advantages nor after-campaigning and consequently complete convergence exists 


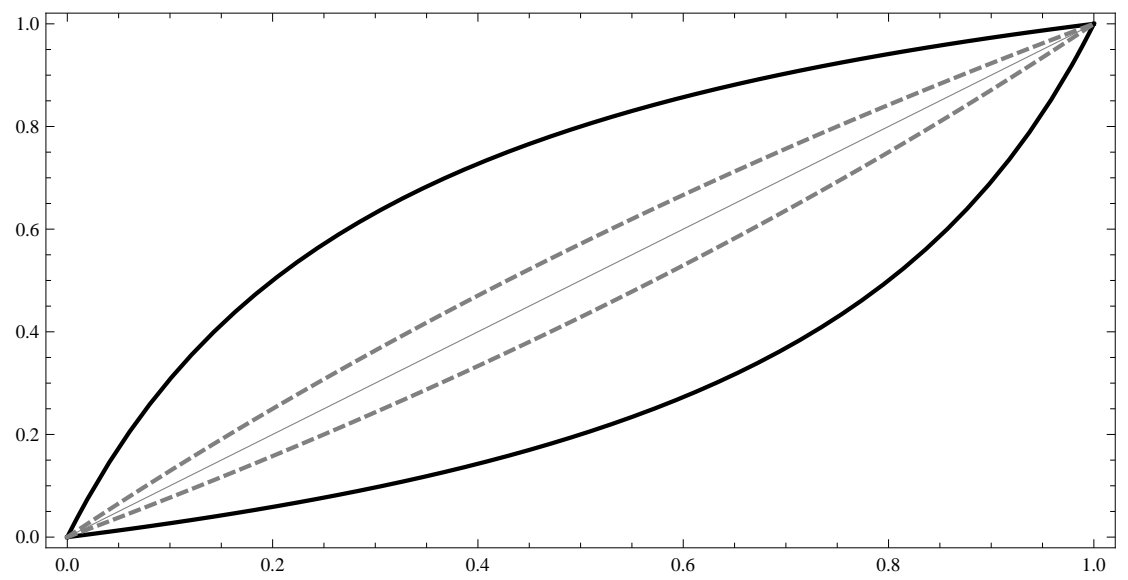

Figure 2: The horizontal axis depicts $\theta^{S}$ and the vertical $\theta^{H} \cdot R=1 / 4$ (black, solid) and $R=3 / 4$ (gray, dashed). If (but not only if) $\theta^{H}$ lies outside the elliptic region between the solid curves for a given $\theta^{S}$, candidates specialize on their comparative advantages. If $R$ becomes smaller (larger), the elliptic region becomes larger (smaller). In the limit, as $R \rightarrow 1$, the region converges to the straight line with $\theta^{H}=\theta^{S}$.

in an interior equilibrium. Also note that this does not depend on the exact shape of the belief distribution: The result is invariant to all mean-preserving modifications of the belief distributions 14

Campaigning theories so far suggested that a convergence equilibrium is not possible, because it cannot be in the interest of competing candidates to highlight the same set of issues. Indeed, this argument has some intuitive appeal. However, as I just showed we might need to reconsider things and look at them from a slightly different angle. The model suggests that theory so far might be missing out something significant, and the empirical record seems to support that.

We saw that comparative advantages determine which candidate spends more on an issue in the campaign. This comparative advantage is defined in equilibrium, i.e. taking into account communication strategies. A natural question that arises now is how before and aftercampaigning comparative advantages are related. It is easy to show and also intuitive that when comparative advantages are 'large' they are persistent as well. That is, before and aftercampaigning comparative advantages are identical. In Figure 2 such a situation is depicted graphically for $n=2$ and an electorate with uniform preferences. However, when $\sigma^{i}$ is close to zero, comparative advantages may change endogenously as the campaign evolves. This resembles recent findings regarding endogenous comparative advantages in trade theory, e.g. Costinot

\footnotetext{
${ }^{14}$ However, those modifications effect the absolute amount spent on the issues. More on that in Section 5
} 
(2009) or Garfinkel. Skaperdas, and Syropoulos (2009). An example of such a situation will be discussed later in Section 6.

We have seen under which conditions two candidates follow similar strategies or different strategies, and which candidate spends more on a given issue. Another important question is which set of issues will be important during a candidate's campaign. That is, on which set of issues will a given candidate put the highest emphasis, which are the issues on which he campaigns with the highest intensity? At first glance, it seems intuitive that a candidate puts the highest emphasis on the issues in which he is perceived competent and less on others. This intuition is again in line with the dominance principle and also with the models of Amorós and Puy (2013) or Aragonès, Castanheira, and Giani (2014). In the present model this turns out to be different:

Proposition 2. A candidate may be forced by competitive pressure to campaign hardest on issues in which he is considered weak, even on his weakest.

This is a puzzling result. The fundamental message of the proposition is that candidates may campaign hardest on any issue, irrespective of whether they are perceived competent in that issue or not. Of course, it does not only apply to the weakest issue but to any issue in which a candidate is perceived weak. To my knowledge, the result contradicts all findings in the extant literature. The dominance principle due to Riker says a candidate should not spend anything on his weakest issue. The recent theoretical analyses of Amorós and Puv (2013) and Aragonès, Castanheira, and Giani (2014) come to a similar finding if one restricts focus to pure strategy equilibria. In these studies campaigning on a weak issue only primes that issue and hence must be detrimental, because the weakest issue is also always a comparative disadvantage. However, once policy advertising is taken into account, this changes drastically.

To illustrate the mechanism and intuition for the proposition, consider the following example. Suppose there are two issues only, one issue is extremely important and the other is rather marginal. Because policy advertising is important, both candidates have a strong incentive to campaign heavily on the important issue, since the issue's importance in the voters' eyes magnifies the impact of spending compared to the other issue, unless one candidate dominates the important issue clearly. Likewise, the less important issue receives not as much attention or may be neglected altogether. Hence, both candidates focus attention on the important issue. However, since there are only two issues, that issue must be one candidate's weakest issue. This 
is a simple and intuitive mechanism, which was not uncovered yet. The empirical record seems to point to its relevance, see for example Green and Hobolt (2008).

\subsection{Agenda setting}

Another important question relating to political campaigning is agenda setting. The political agenda can be interpreted as a list of the most salient issues and this list is to some degree determined during the political campaign. This agenda is important because each candidate's chances to succeed at the ballot are better when their good issues receive a high priority in the campaign and thus a higher issue weight. The agenda is also important because it impacts which set of issues receive a high priority after Election Day and hence which policies are implemented.

The question which issue dominates the campaign is influenced by many different things and hence not easy to answer in a general way. In this section I will show that issues need not-and in fact often are not-targeted according to the electorate's estimates of issues' importance. In other words: issues of secondary importance may receive the bulk of attention, while more important issues are neglected. Indeed, even the most extreme ranking of issues may emerge during the campaign:

Proposition 3. Issues may be targeted in reverse order of their importance. The constituents' feelings about the most pressing issues are often not reflected by the agenda.

How campaigning determines the agenda hinges on a relatively complicated mixture of competence beliefs and issue importance weights. The proposition tells us that, in principle, any ranking of issues is conceivable, depending on those beliefs, although greater importance-ceteris paribus-tends to increase the intensity with which an issue is targeted during the campaign. This result seems puzzling and hence it is important to explain why this might be the case. Before we discussed under which conditions one candidate spends more on an issue than his opponent, and found that this relates to comparative advantages. The reason was is that if there are comparative advantages, priming has a differential effect on candidates spending incentives-it increases the incentive for one and at the same time decreases the incentives of the other. Now, however, we want to understand under which conditions the aggregate of spending is higher in one issue than in another. Hence, we compare two issues and not two candidates with issues kept constant. And thus we need to understand what determines aggregate spending on a given 
issue.

To develop an intuition for what determines aggregate spending on an issue, take another look at the FOCs in (7). Two effects determine how much a given candidate spends on an issue: issue priming and policy advertising. Policy advertising is very similar for both, while issue priming decreases incentives for one candidate and decreases incentives for the other. In particular, note that the two issue priming effects cancel each other out. It increases the FOC by the exact same amount for the one candidate as it decreases the FOC for the other. But this makes aggregate incentives to spend on an issue easier to grasp: they depend mostly on policy advertising. To see how that might explain the proposition, suppose $g^{\prime}(x)=0$ and thus that there is no issue priming. Hence, $w^{i}=\omega^{i}$ and the only strategically interesting interaction is policy advertising. For simplicity of argument suppose in addition that there is only one type of voters. It is easy to see that in that case both spend the same on each issue (because there is no issue priming effect). Then, two parameters of interest determine spending: the issue's weight $\omega^{i}$ and a measure of how decided the voter is on issue $i$ with respect to which candidate is more competent, $\theta^{i}\left(1-\theta^{i}\right)$. If the latter is large (close to $\left.1 / 4\right), \theta^{i}$ is close to $1 / 2$ and hence the voter is unsure which candidate serves his interests better. If it is close to zero, the voter has a clear favorite. In the latter case, advertising is not very effective because the voter is already relatively determined, while the opposite is true in the former case. But of course also $\omega^{i}$ plays an important role. Intuitively, when $\varrho^{i}:=\omega^{i} \theta^{i}\left(1-\theta^{i}\right)$ is large, spending on issue $i$ tends to be high, while it is low else. It is straightforward to show that an issue receives more advertising when $\varrho$ increases. Hence, issue $i$ receives more advertising during the campaign than issue $j$ whenever $\varrho^{i}>\varrho^{j}$, irrespective of which issues is more important to voters. A less important issue is featured more during a campaign than a more important issue whenever the difference in the voter's competence assessments overcompensates for the difference in importance.

What is the main takeaway from this section? We have seen that the political agenda need not be correlated at all to issues' ex-ante importance weights, but it might as well be, if competitive pressure aligns campaigning incentives with constituents' needs. This tells us two things. First, we cannot understand agenda formation based solely on information about which issues are pressing at a given time. Competitive pressure also influenced by candidates' ascribed competence levels in the different issues, and this may set an agenda that is even inversely related to ex-ante importance weights. Indeed, in reality we oftentimes see issue getting a top spot on 
the political agenda although the electorate deems those issues rather irrelevant or of secondary importance. Examples abound, one particularly appealing point in case can be found during the 2008 presidential campaign between Barack Obama and John McCain. The issue 'Taxes' was, according to constituents' beliefs, not among the top 5 issues at the time. But is was the most important issue during the campaign, with both candidates spending more than 20 percent of their campaign budget on TV advertising related to their tax policies. In general, the rank correlation between constituents' issue rankings and the ranking in the campaign was 0.39 , which is positive but not significantly different from zero 15 In other studies like Green and Hobolt (2008) the correlation is higher, but in general there are often stark differences between actual campaign agendas and constituents' beliefs.

Second, the result relates to the welfare implications of campaigning for two reasons. On the one hand, issues of secondary importance might decide the election. This in turn might lead to a suboptimal selection on Election Day. Politicians want to manipulate voters during a campaign and often distract their attention from what might be important. On the other hand, campaigning influences the political agenda also after Election Day. If campaign agendas turn out to be persistent, they might not only influence political selection but also which policies are actually implemented. Competitive pressure during the campaign that makes candidates focus on issues of secondary importance may also distort policy making. Both the selection argument and the policy argument point to potential weaknesses of the democratic process due to campaigning.

\section{Discussion}

\subsection{The importance of the belief distribution}

A point that deserves attention is the influence of the particular shape of voters' beliefs. We have seen that comparative advantages are determined by the first moments of the conditional distributions of beliefs (that is, the weighted average of candidates' relative competence in each issue). Since comparative advantages determine whether there is polarization or convergence in communication strategies, the higher moments of the belief distribution do not play a role for this question. But of course the higher moments must have some effect on candidates' spending.

\footnotetext{
${ }^{15}$ The t-statistic is 0.9552 , implying the p-value for the one sided test is in the range of $p=0.2$.
} 
While the higher moments of the belief distribution do not have an influence on whether there is divergence, they effect agenda setting (for fixed means). To see why and in what way, focus on the conditional distribution of competence beliefs and remember that a given voter is more easily swayed the more undecided he is between candidates. This is captured by $\theta_{v}^{i}\left(1-\theta_{v}^{i}\right)$. If $\theta_{v}^{i}$ is close to $1 / 2$, advertising is relatively effective, otherwise it is not. Hence, in a situation in which there are two voters and both belief $\theta_{v}^{i}=1 / 2$, spending tends to be higher than if the same two voters had beliefs $1 / 4$ and $3 / 4$, although the average belief is identical in both situations. In these situations increasing the variance of the distribution while keeping the mean fixed tends to decrease spending on that issue.

Note that such an increase in the variance of the conditional distribution also affects spending on other issues. When an increase of the variance leads to decreased spending, the issue's relative importance decreases as well because the issue is primed less. Consequently, ceteris paribus the relative importance of the other issues needs to increase, implying higher spending on those. Such a situation is depicted in Figure 3 .

To sum up, the higher moments of the belief distribution matter for agenda setting. Increasing the variance of the distribution may have two different effects, depending on whether constituents clearly favor one candidate or not. What do we learn from this result? We have seen before that with respect to agenda setting we cannot simply look at the most important issues to determine campaigning agendas, but have to take into account also how voters evaluate candidates in the different issues. The discussion in this section confirms these findings. The political agenda is determined by the intricate interplay of many forces. However, regarding convergence or divergence, the higher moments are negligible.

\subsection{Differences in marginal costs}

In many campaigns candidates exhibit significant differences unrelated to their political reputation (the $\theta$ s), but which pertain to their strength during the campaign: differences in marginal costs. When a candidate has lower marginal costs than her opponent, she can more easily raise funds and hence spend more during the campaign. For example, when looking at the 2008 campaign in the US between Barack Obama and John McCain, it becomes apparent that Obama had a significant advantage due to a greater campaigning purse 16 This kind of difference of

\footnotetext{
${ }^{16}$ See, for example www.fec.org.
} 


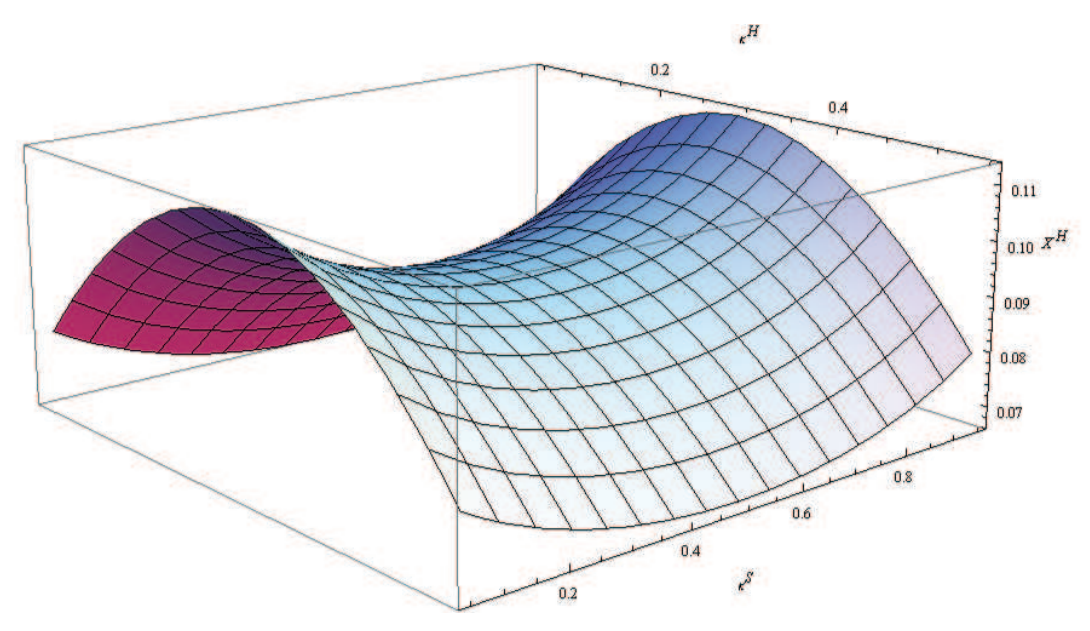

Figure 3: Aggregate spending on issue $H$ as a function of the variance of voters' beliefs. I assumed $f(x)=\sqrt{\frac{1}{1000}+x}, g(x)=\sqrt{\frac{1}{10}+x}, \underline{\theta}^{H}=\frac{4}{10}+\kappa^{H}, \bar{\theta}^{H}=1-\kappa^{H}, \bar{\theta}^{S}=1-\kappa^{S}, \underline{\theta}^{S}=\kappa^{S}, \bar{\omega}=\frac{55}{100}$, $\underline{\omega}=\frac{45}{100}, q^{H}=\frac{1}{2}, q^{S}=\frac{1}{2}$, and $q^{w}=\frac{1}{2}$. $X^{H}$ denotes aggregate spending on issue $H$. It is easy to see that aggregate spending is hump-shaped in $\kappa^{H}$ and $\mathrm{U}$-shaped in $\kappa^{S}$, and the respective maximum and minimum are, as predicted, at $\kappa^{H}=\frac{\bar{\alpha}^{H}-\underline{\alpha}^{H}}{2}=\frac{3}{10}$ and $\kappa^{S}=\frac{\bar{\alpha}^{S}-\underline{\alpha}^{S}}{2}=\frac{1}{2}$.

course matters for conclusions, because if one candidate has a significant marginal cost advantage, she might simply spend more on all issues. To get to sharp conclusions as before we need to consider a definition of comparative advantage that is augmented for marginal cost differences.

Denoting by $\gamma_{k}$ candidate $k$ 's marginal costs of campaigning, first order conditions look now as

$$
\begin{aligned}
\frac{\partial \pi_{1}(\mathbf{x} ; s)}{\partial x_{1}^{i}} & =E_{\mathcal{S}}\left[\frac{\partial c_{v}^{i}(\mathbf{x} ; s)}{\partial x_{1}^{i}} w_{v}^{i}(\mathbf{x} ; s)+\sum_{j \neq i}\left(c_{v}^{j}(\mathbf{x} ; s)-c_{v}^{i}(\mathbf{x} ; s)\right) \frac{\partial w_{v}^{j}(\mathbf{x} ; s)}{\partial x_{1}^{i}}\right]-\gamma_{1} \stackrel{!}{=} 0 \\
\frac{\partial \pi_{2}(\mathbf{x} ; s)}{\partial x_{2}^{i}} & =E_{\mathcal{S}}\left[-\frac{\partial c_{v}^{i}(\mathbf{x} ; s)}{\partial x_{2}^{i}} w_{v}^{i}(\mathbf{x} ; s)-\sum_{j \neq i}\left(c_{v}^{j}(\mathbf{x} ; s)-c_{v}^{i}(\mathbf{x} ; s)\right) \frac{\partial w_{v}^{j}(\mathbf{x} ; s)}{\partial x_{1}^{i}}\right]-\gamma_{2} \stackrel{!}{=} 0
\end{aligned}
$$

With identical marginal costs $\sigma^{i}=0$ signifies not only comparative advantages but also which candidate spends more on an issue. Differences in marginal costs complicate matters a bit, but we can nevertheless state the following: 
Proposition 4. Let $\Delta:=\gamma_{1}-\gamma_{2}$. Candidate 1 spends more on issue $i$ than candidate 2 if

$$
\sigma^{i}+\phi^{i}(\Delta)>0
$$

less if $\sigma^{i}+\phi^{i}(\Delta)<0$, and as much if $\sigma^{i}+\phi^{i}(\Delta)=0$, where $\frac{d \phi^{i}(\Delta)}{d \Delta}<0$ and

$$
\operatorname{Sign}\left[\phi^{i}(\Delta)\right]=\left\{\begin{array}{cc}
"+{ }^{\prime \prime} & \text { if } \Delta<0 \\
0 & \text { if } \Delta=0 \\
"-\text { " } & \text { if } \Delta>0
\end{array}\right.
$$

$\phi^{i}(\Delta)$ is a term that augments $\sigma^{i}$ by taking into account additional information such as the difference in marginal costs but also other information such as the beliefs of the electorate. Candidate 1 has a marginal cost advantage if $\Delta<0$. Such an advantage creates an additional tendency to spend more on an issue for quite straightforward reasons. Of course it might be the case that comparative advantages go against marginal cost advantages and in that case the respective magnitude is important to determine which candidate spends more on an issue. Also, unlike before, it may now be the case that there are comparative advantages in all issues but that one candidate dominates all issues when it comes to spending. Assume we can rank issues in such a way that $\theta_{1}>\theta_{2}>\cdots>\theta_{n}$, implying candidate 1 has a comparative advantage in issue 1 and a comparative disadvantage in issue $n$. Also assume that $\Delta<0$. Then, if $\phi^{n}(\Delta)>-\sigma^{n}$ candidate 1 spends more on all issues.

Corollary 2. Iff $\Delta \neq 0$, one candidate might spend more on all issues.

Note that $\phi^{i}(\Delta)$ depends on many things like the electorate's beliefs and the advertising technology, not only on $\Delta$. Thus it is not straightforward to determine its absolute value in general. It tends to increase in $\omega_{v}^{i}$, a voter's pre-campaigning assessment of issue $i$ 's importance. The reason is that the absolute value of $\sigma^{i}$ tends to be greater when the issue is more important. In other words, starting from a situation in which $\sigma^{i}=0$ and increasing $\theta^{i}$ by a bit will have a greater impact on $\sigma^{i}$ when $\omega^{i}$ is large.

In empirical applications scholars often circumvent the problem of marginal cost differences 

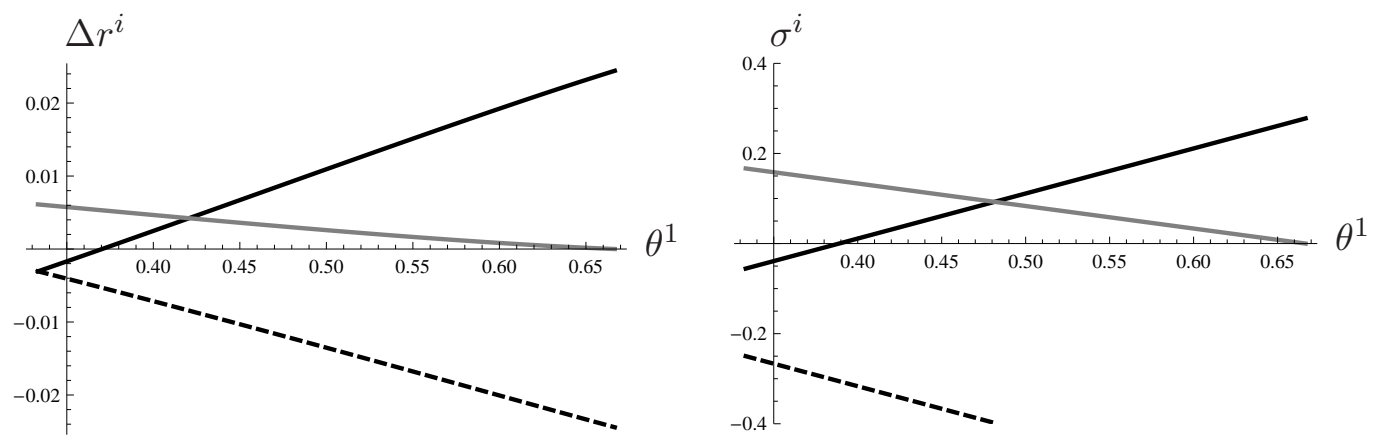

Figure 4: In the left panel we can see the predicted differences in budget share devoted to the respective issues as $\theta^{1}$ increases from 0.3 to 0.7 , while the right panel shows comparative advantages. As we can see the trajectories are not identical but similar. Especially, the zeros of the respective corresponding curves are attained at quite similar values of $\theta^{1}$.

in another way, because a statement of the form " 1 puts a greater emphasis on issue $i$ than 2 " is meaningless if emphasis is measured by the absolute amount of spending when endowments/costs differ significantly. Sigelman and Buell (2004) or Kaplan. Park, and Ridout (2006) discuss that focussing on the differences of the share of their total budget that candidate uses to campaign on a given issue is a much more meaningful measure of emphasis. This measure can be defined in the following way:

$$
\Delta r^{i}:=\frac{x_{1}^{i}}{\sum_{j=1}^{n} x_{1}^{j}}-\frac{x_{2}^{i}}{\sum_{j=1}^{n} x_{2}^{j}}
$$

If $\Delta r^{i}>0$, candidate 1 puts greater emphasis on issue $i$ because he devotes a greater share of his campaigning purse to that issue than does candidate 2. Of course this measure was not developed using the model I propose, but comparative advantage as defined here does well in predicting which candidate puts greater emphasis on which issue. For an example with $n=3$, see Figure 4. In the left panel the difference in the fractions of the total campaign purse devoted to an issue is depicted,

$$
\Delta r^{i}=\frac{x_{1}^{i}}{x_{1}^{1}+x_{1}^{2}+x_{1}^{3}}-\frac{x_{2}^{i}}{x_{2}^{1}+x_{2}^{2}+x_{2}^{3}} .
$$

The right panel shows after-campaigning comparative advantages, $\sigma^{i}$. In both cases the exogenous variable is $\theta^{1}$. While $\Delta r^{i}$ is certainly not a precise measure of which candidates focusses on which issue in the logic of the model, it often yields a good approximation. In addition, For example, if we feed the model with the data from the Gallup survey mentioned above and numerically solve for equilibrium budget shares devoted to the different issues, the model is able to correctly predict which candidate put greater emphasis on which issue (out of 
six) in the 2008 campaign between Barack Obama and John McCain, see Table ?? (t.b.d.). While Barack Obama held absolute advantages in most issues, he held comparative advantages only in the issues 'economy' and 'health care'. Marginal costs in the model were chosen such that the model correctly predicts the spending gap between the two candidates (Obama spent roughly 70 per cent more during the campaign, see www.fec.com). According to the model Obama devoted a greater share of his budget to the two issues in which he had comparative advantages. The issue taxes was a very close call and Obama held a pre-campaigning comparative advantage in most specifications. However, the absolute value of the comparative advantage was very small (the smallest among all issues) and the after campaigning comparative advantage in this issue indeed changed (but remained small). Comparing this to the candidates' actual spending data, these six predictions can actually be verified. Maybe most puzzling, the model correctly predicts the quite narrow gap in relative spending on the issue 'taxes'.

\subsection{The effect of the media}

We have seen that under quite general conditions candidates follow their comparative advantages in their communication strategies. But while candidates have of course some influence in determining the campaign agenda, they represent only one side of the communication market, and another important part, the media, was neglected so far. The coverage of topics by media companies such as TV stations and newspapers certainly has an important impact on constituents' perceptions about issues relative importance and candidates' relative competence or policy quality, even if media companies are unbiased in their reporting. However, this does not have an effect on candidates' behavior if we assume candidates take as given what the media does. Media coverage, seen as an exogenous variable, can be interpreted as one force that influences voters' beliefs, which is probably also a correct interpretation. In this interpretation the model's predictions do not change. If we take the different position and assume candidates have an influence on what the media reports about, we are basically back in the model as well, because influencing the media who then addresses an issue is one form of communication for the candidates and as such is also part of the model. The impact functions defined in Assumption 1 and 2 can be interpreted to represent this channel. Hence, although it is interesting to study the impact of the media during political campaigns, it can be interpreted as being in the model's 
background and hence the model's predictions do not change.

\section{Conclusion}

In this paper, I have develop a model of multi-issue candidate competition that focuses on campaign spending when issue priming and policy advertising are important. Incorporating these two effects in one model of political competition is the main contribution of the paper and allows to generate novel predictions about campaign communication strategies, that seem to be more in line with the empirical record than those of earlier theories.

The main takeaways are the following: Issue priming creates a tendency for candidates to put greater focus on their comparative advantages, but policy advertising at the same time creates incentives to compete also on other issues. Hence, imperfect convergence in the issues in an interior equilibrium is generally possible. Second, a candidate may be forced by competitive pressure to put the greatest emphasis on issues in which he is perceived weak. Finally, to correctly predict the political agenda during a campaign, one needs to take into account more than just information about which issues are important, but also how competent voters consider the different candidates in the different issues. Even a political agenda that turns voters' sentiment regarding issues' importance upside down is possible. Hence, candidates may lose touch with the electorate due to competitive pressure.

The main predictions of the model are at odds with those of existing models of campaign communication, especially issue ownership theory due to Petrocik (1996) and Simon (2002) and the dominance and dispersion principle due to Riker (1996). However, these theories are also at odds with observed campaigning behavior:

Issue ownership theory clearly requires further development before it can systematically help us understand campaigns. Simon's model provides little leverage in accounting for the level and variance of issue convergence observed since it results in a corner solution predicting no issue convergence. When we define owned issues in a manner consistent with Petrocik (1996), we find that issue ownership has no statistically significant relationship with the extent of issue convergence.

Kaplan, Park, and Ridout (2006) 
The presented model augments existing theories by taking into account policy advertising in addition to issue priming. The predictions seem to fit the empirical record better and it provides an explanation for the frequently observed phenomenon of imperfect divergence in communication strategies.

The model opens up several avenues for future research. First, a number of novel predictions were developed that still have to stand the empirical test. Second, the model takes as given policy platforms and party ideologies. In a further theoretical studies it will be interesting to study the strategic repercussions of the campaign for optimal platform choice and party formation.

\section{Appendix}

\section{A Psychological underpinnings}

\section{A.1 Policy advertising and the mere-exposure effect}

Policy advertising is modeled as purely persuasive and assumed to be effective. This assumption is quite common and many scholars follow this approach, e.g. Snvder (1989), and Iaryczower and Mattozzi (2011, 2013). Mueller and Stratmann (1994) argue that this form of advertising is also the most important form of political advertising. Economists also frequently use models of purely persuasive advertising, which Johnson and Mvatt (2006) call 'hype', e.g. Bühler and Halbheer (2011, 2012). See also the survey by Bagwell (2007).

The assumption of persuasive advertising is not as ad-hoc as it may seem very often, but has a deep rooting in cognitive psychology, and scholars often refer to this phenomenon as the mere-exposure effect, which says that "repeated exposure to an object results in greater attraction to that object" (Hogg and Vaughan, 2008), because it creates familiarity. This effect was first systematically described by Zajond (1968). He conducted two experiments with a counterbalanced measure design that ought to establish the effect. In the first, twelve seven letter Turkish words were exposed to a number of subjects either once, twice, five times, ten times or 25 times for two seconds a time. At each exposure subjects were told how to correctly pronounce the word and asked to repeat it. The goal of the study was said to be studying the learning capabilities of subjects. At the end of the experiment subjects were told that each word was a Turkish adjective with either a positive or negative meaning and were asked to rate the goodness of the meaning 
on 7 point $(0-6)$ scale. He derived a strong and statistically significant effect $(p<0.001)$ of mere exposure, but with diminishing marginal effects. Because learning to pronounce may also be the reason for the effect he did the same experiment again with Chinese characters instead of Turkish words and the results very much resembled those from the first experiment.

Many authors have worked on the mere-exposure effect in very different scenarios since, e.g. Zaiono (1980, 2001), Harmon-Jones and Allen (2001), Tom. Nelson, Srzentic, and King (2007), Moon. Mackie, and GarciaMarques (2009), and Jones (1999), and found the effect is persistent. Serenko and Bontis (2011) found strong evidence that researchers' quality rating of academic journals increases with exposure as well. In a meta-study of more than 200 experiments on the subject, Bornstein (1989) found that the effect is robust and positive, but also confirmed that the marginal effect of exposure is decreasing. Hence, the effect is strongest (at the margin) when individuals are completely unfamiliar with a stimulus.

What does this effect imply for policy advertising? It means that, for example, Obama repeatedly stating that the 'Affordable Health Care for America Act' is good for the country will increase individuals attraction to actually adopting such a policy. However, with decreasing marginal impact. Hence, we can interpret the mere-exposure effect as a psychological foundation of the persuasion technology introduced in Assumption 1 .

\section{A.2 Priming}

In psychological terms, priming is a cognitive process that activates accessible categories in the mind of a person. Exposure to a stimulus makes the related categories of the stimulus easier accessible and the categories become more important in the mind of individuals. This effect may be long lasting - up to 24 hours - and is quite subtle. People often do not realize that they were primed (see e.g. Hogg and Vaughan (2008)). Smith and Mackie (2007) put it in the following way: "[...] anything that brings an idea to mind-even coincidental, irrelevant events-can make it accessible and influence our interpretation of behavior" (page 67). In the specific example of a political campaign, priming makes an issue more salient and thus individuals evaluate the issue as more relevant for making decisions (see Iyengar and Kinder (1987) or Weaver (2007)). Priming is hence closely related to the theory of agenda setting (see for example the discussion in Willnat (1997)). In deciding between alternatives, the primed issue is still in the memory and becomes 
more important. Priming can therefore "alter the standards by which people evaluate election

candidates" (Severin and Tankard, 1997). In that sense, priming theory can be interpreted as a psychological foundation of the issue priming contest as defined in Assumption 2.

\section{B Technical Appendix}

\section{B.1 Existence of Equilibrium}

Proof. Proving existence of equilibrium is a bit intricate, because due to the complexity of the problem at hand, it is not really possible to characterize the shape of the individual payoff functions. Hence, I will simplify the problem a bit and show that starting from this simplified problem, payoff function must behave similarly in a sufficiently close neighbourhood.

Before getting started with the more complicated part, note that each candidates relevant strategy space is a subset of $[0,1]^{n}$, because effort larger than 1 is strictly dominated by spending nothing at all. This strategy space is convex and compact. Also note that individual payoff functions are continuous in all variables. To ensure existence of a pure strategy Nash equilibrium it hence suffices to show that payoff functions are strictly concave (which is easier to show than strictly quasi-concave, which would also be sufficient).

To show concavity, I assume i) that there is a parameter $\zeta$ governing the magnitude of the all derivatives of $g(. \mid \zeta)$ and that the derivatives of $g(. \mid \zeta)$ are continuous in $\zeta$. I also assume

$$
\frac{d g^{\prime}(. \mid \zeta)}{d \zeta}<0 \forall \zeta<\bar{\zeta}
$$

that ii) $g(x \mid \zeta)$ is $\mathcal{C}^{2}$, and that $\frac{d g^{\prime}(. \mid \zeta)}{d \zeta}=g^{\prime}(. \mid \zeta)=0$ if $\zeta \geq \bar{\zeta}$ for some $\bar{\zeta}$. I assume first $\zeta=\bar{\zeta}$ and show that the result holds. I then argue that a continuity argument proves that the result must also hold for some $\zeta<\bar{\zeta}$. If $\zeta=\bar{\zeta}, g^{\prime}(x)=0$ and thus the campaign revolves only around policy advertising.

A candidate's payoff function is strictly concave, if the Hessian is negative definite, i.e. if the leading principal minors $d^{k}$ of the Hessian alternate in sign and $d^{1}<0$. Consider the first derivative of a candidate's payoff function with respect to $x_{j}^{i}$ : 


$$
\begin{aligned}
\frac{\partial \pi_{j}(\mathbf{x} ; \mathcal{S})}{\partial x_{j}^{i}} & =E_{\mathcal{S}}\left[\frac{\partial c_{v}^{i}(\mathbf{x} ; \mathcal{S})}{\partial x_{j}^{i}} w_{v}^{i}\right]-\gamma \\
& =E_{\mathcal{S}}\left[\frac{\theta_{v}^{i}\left(1-\theta_{v}^{i}\right) f^{\prime}\left(x_{j}^{i}\right) f\left(x_{-j}^{i}\right)}{\left(\theta_{v}^{i} f\left(x_{1}^{i}\right)+\left(1-\theta_{v}^{i}\right) f\left(x_{2}^{i}\right)\right)^{2}} w_{v}^{i}\right]-\gamma
\end{aligned}
$$

This is independent of all $x_{j}^{-i}$ and hence all

$$
\frac{\partial^{2} \pi_{j}(\mathbf{x} ; \mathcal{S})}{\partial x_{j}^{i} \partial x_{j}^{k}}=0 \forall k \neq i
$$

Therefore, all entries except those on the main diagonal are zero and the Hessian is a diagonal Matrix. The determinant of a diagonal matrix equals the product of the elements on the diagonal. To determine the sign the second derivatives we hence only need to check

$$
\begin{aligned}
\frac{\partial^{2} \pi_{j}(\mathbf{x} ; \mathcal{S})}{\partial\left(x_{j}^{i}\right)^{2}} & =E_{\mathcal{S}}\left[\frac{\partial^{2} c_{v}^{i}(\mathbf{x} ; \mathcal{S})}{\partial\left(x_{j}^{i}\right)^{2}} w_{v}^{i}\right] \\
& =E\left[\frac{\theta_{v}^{i}\left(1-\theta_{v}^{i}\right) f\left(x_{-j}^{i}\right)\left[f^{\prime \prime}\left(x_{j}^{i}\right)-2\left(\theta_{v}^{i} f\left(x_{1}^{i}\right)+\left(1-\theta_{v}^{i}\right) f\left(x_{2}^{i}\right)\right) f^{\prime}\left(x_{j}^{i}\right)^{2}\right]}{\left(\theta_{v}^{i} f\left(x_{1}^{i}\right)+\left(1-\theta_{v}^{i}\right) f\left(x_{2}^{i}\right)\right)^{3}}\right]
\end{aligned}
$$

If (but not only if)

$$
f^{\prime \prime}\left(x_{j}^{i}\right)-2 f(1) f^{\prime}\left(x_{j}^{i}\right)^{2}<0 \forall x_{j}^{i} \in[0,1]
$$

this second derivative is strictly negative. The condition is similar to log-concavity of $f(x)$ but somewhat more restrictive. It allows for both increasing as well as decreasing returns in policy advertising $f(x) . f^{\prime \prime}(x)<0$ trivially assures that the inequality holds.

If (B.1) holds and $\zeta=\bar{\zeta}$, each candidate's payoff function is strictly concave in his own strategy. Each entry on the main diagonal of the Hessian is negative and the leading principal minors alternate in sign. Note that when $\zeta=\bar{\zeta}, g^{\prime}(x \mid \bar{\zeta})=0$ and hence also $g^{\prime \prime}(x \mid \bar{\zeta})=0$. Since the determinant of a square matrix is a continuous function of its entries, which can be seen for example using the Leibniz formula for determinants, and all entries are continuous in $\zeta$, the determinant must also be continuous in $\zeta$. Hence, if (B.1) holds, the candidates' payoff functions must be strictly concave in their own efforts also in a neighbourhood of $\bar{\zeta}$ for some $\zeta<\bar{\zeta}$. This assure existence of pure strategy equilibrium in this neighbourhood by the Debreu, Glicksberg, and Fan (1952) theorem (see for example Theorem 1.2 in Fudenberg and Tirole (1991)). If in 
addition $f^{\prime}(0)$ sufficiently large, an interior pure strategy equilibrium exists, which can easily be seen from the first order conditions (unless $E_{\mathcal{S}}\left[\theta_{v}^{i}\left(1-\theta_{v}^{i}\right) w_{v}^{i}\right]=0$, which is excluded by assumption) .

\section{B.2 Proof of Proposition 1]}

Proof. Remember from (17) that the first order conditions in issue $i$, which have to hold in an interior equilibrium, can be written as

$$
\begin{aligned}
\frac{\partial \pi_{1}(\mathbf{x} ; s)}{\partial x_{1}^{i}} & =E_{\mathcal{S}}\left[\frac{\partial c_{v}^{i}(\mathbf{x} ; s)}{\partial x_{1}^{i}} w_{v}^{i}(\mathbf{x} ; s)+\sum_{j \neq i}\left(c_{v}^{j}(\mathbf{x} ; s)-c_{v}^{i}(\mathbf{x} ; s)\right) \frac{\partial w_{v}^{j}(\mathbf{x} ; s)}{\partial x_{1}^{i}}\right]-\gamma \stackrel{!}{=} 0 \\
\frac{\partial \pi_{2}(\mathbf{x} ; s)}{\partial x_{2}^{i}} & =E_{\mathcal{S}}\left[-\frac{\partial c_{v}^{i}(\mathbf{x} ; s)}{\partial x_{2}^{i}} w_{v}^{i}(\mathbf{x} ; s)-\sum_{j \neq i}\left(c_{v}^{j}(\mathbf{x} ; s)-c_{v}^{i}(\mathbf{x} ; s)\right) \frac{\partial w_{v}^{j}(\mathbf{x} ; s)}{\partial x_{1}^{i}}\right]-\gamma \stackrel{!}{=} 0
\end{aligned}
$$

After simple manipulations we can rewrite this as

$$
E_{\mathcal{S}}\left[\left(\frac{\partial c_{v}^{i}(\mathbf{x} ; s)}{\partial x_{1}^{i}}+\frac{\partial c_{v}^{i}(\mathbf{x} ; s)}{\partial x_{2}^{i}}\right) w_{v}^{i}(\mathbf{x} ; s)\right]=-2 E_{\mathcal{S}}\left[\sum_{j \neq i}\left(c_{v}^{j}(\mathbf{x} ; s)-c_{v}^{i}(\mathbf{x} ; s)\right) \frac{\partial w_{v}^{j}(\mathbf{x} ; s)}{\partial x_{1}^{i}}\right]
$$

The RHS relates to comparative advantages, the LHS to differences in spending, as I will show now.

Take a look at the LHS first:

$$
\begin{aligned}
& E_{\mathcal{S}}\left[\left(\frac{\partial c_{v}^{i}(\mathbf{x} ; s)}{\partial x_{1}^{i}}+\frac{\partial c_{v}^{i}(\mathbf{x} ; s)}{\partial x_{2}^{i}}\right) w_{v}^{i}(\mathbf{x} ; s)\right]=E_{\mathcal{S}}\left[\frac{\theta_{v}^{i}\left(1-\theta_{v}^{i}\right)\left\{f^{\prime}\left(x_{1}^{i}\right) f\left(x_{2}^{i}\right)-f\left(x_{1}^{i}\right) f^{\prime}\left(x_{2}^{i}\right)\right\}}{\left(\theta_{v}^{i} f\left(x_{1}^{i}\right)+\left(1-\theta_{v}^{i}\right) f\left(x_{2}^{i}\right)\right)^{2}} w_{v}^{i}(\mathbf{x} ; s)\right] \\
& =E_{\mathcal{S}}\left[\frac{\theta_{v}^{i}\left(1-\theta_{v}^{i}\right)}{\left(\theta_{v}^{i} f\left(x_{1}^{i}\right)+\left(1-\theta_{v}^{i}\right) f\left(x_{2}^{i}\right)\right)^{2}} w_{v}^{i}(\mathbf{x} ; s)\right]\left\{f^{\prime}\left(x_{1}^{i}\right) f\left(x_{2}^{i}\right)-f\left(x_{1}^{i}\right) f^{\prime}\left(x_{2}^{i}\right)\right\}
\end{aligned}
$$

The expected value in the first term is strictly positive and hence the sign of the whole expression depends solely on the second term. The second term is positive (negative/zero) whenever $x_{1}^{i}<x_{2}^{i}$ $(>/=)$. This follows from

$$
\frac{d \frac{f^{\prime}(x)}{f(x)}}{d x}=\frac{f^{\prime \prime}(x) f(x)-f^{\prime}(x)^{2}}{f(x)^{2}}<0
$$

whenever $f(x)$ is log-concave, which follows from Assumption 1, Hence, to prove the proposition it remains to be shown that the RHS of $(\underline{B .2})$ is negative whenever candidate 1 has a comparative 
advantage in $i$. Formally

$$
\operatorname{Sign}\left[E_{\mathcal{S}}\left[\sum_{j \neq i}\left(c_{v}^{j}(\mathbf{x} ; s)-c_{v}^{i}(\mathbf{x} ; s)\right) \frac{\partial w_{v}^{j}(\mathbf{x} ; s)}{\partial x_{1}^{i}}\right]\right]=\operatorname{Sign}\left[\sigma^{i}\right]
$$

Straightforward manipulations yield

$$
\begin{aligned}
& \operatorname{Sign}\left[E_{\mathcal{S}}\left[\sum_{j \neq i}\left(c_{v}^{j}(\mathbf{x} ; s)-c_{v}^{i}(\mathbf{x} ; s)\right) \frac{\partial w_{v}^{j}(\mathbf{x} ; s)}{\partial x_{1}^{i}}\right]\right] \\
= & \frac{\omega^{i} g^{\prime}\left(x_{1}^{i}+x_{2}^{i}\right)}{\sum_{k=1}^{n} \omega^{k} g\left(x_{1}^{k}+x_{2}^{k}\right)} \operatorname{Sign}\left[E_{\mathcal{S}}\left[\sum_{j \neq i}\left(c_{v}^{i}(\mathbf{x} ; s)-c_{v}^{j}(\mathbf{x} ; s)\right) w_{v}^{j}(\mathbf{x} ; s)\right]\right] \\
= & \operatorname{Sign}\left[E_{\mathcal{S}}\left[c_{v}^{i}(\mathbf{x} ; s)\left(1-w_{v}^{i}(\mathbf{x} ; s)\right)-\sum_{j \neq i}\left(c_{v}^{j}(\mathbf{x} ; s) w_{v}^{j}(\mathbf{x} ; s)\right)\right]\right] \\
= & \operatorname{Sign}\left[E_{\mathcal{S}}\left[c_{v}^{i}(\mathbf{x} ; s)-c_{v}^{i}(\mathbf{x} ; s) w_{v}^{i}(\mathbf{x} ; s)-\sum_{j \neq i}\left(c_{v}^{j}(\mathbf{x} ; s) w_{v}^{j}(\mathbf{x} ; s)\right)\right]\right] \\
= & \operatorname{Sign}\left[E_{\mathcal{S}}\left[c_{v}^{i}(\mathbf{x} ; s)\right]-E_{\mathcal{S}}\left[\sum_{j=1}^{n} c_{v}^{j}(\mathbf{x} ; s) w_{v}^{j}(\mathbf{x} ; s)\right]\right]=\operatorname{Sign}\left[\sigma^{i}\right] .
\end{aligned}
$$

Hence, candidate 1 spends more on an issue than 2 if he has a comparative advantage, less if he has a disadvantage, and as much else.

\section{B.3 Proof of Proposition 2}

Proof. To prove the proposition I show that if one issue is extremely important relative to all others, this issue receives the bulk of attention from both candidates, independent of candidates' competence levels. The rest follows immediately.

Look again at the FOCs in issue $i$ :

$$
\begin{aligned}
\frac{\partial \pi_{1}(\mathbf{x} ; \mathcal{S})}{\partial x_{1}^{i}} & =E_{\mathcal{S}}\left[\frac{\partial c_{v}^{i}(\mathbf{x} ; \mathcal{S})}{\partial x_{1}^{i}} w_{v}^{i}(\mathbf{x} ; \mathcal{S})+\sum_{j=1}^{n} c_{v}^{j}(\mathbf{x} ; \mathcal{S}) \frac{\partial w_{v}^{j}(\mathbf{x} ; \mathcal{S})}{\partial x_{1}^{i}}\right]-\gamma \stackrel{!}{=} 0 \\
\frac{\partial \pi_{2}(\mathbf{x} ; \mathcal{S})}{\partial x_{2}^{i}} & =E_{\mathcal{S}}\left[-\frac{\partial c_{v}^{i}(\mathbf{x} ; \mathcal{S})}{\partial x_{2}^{i}} w_{v}^{i}(\mathbf{x} ; \mathcal{S})+\sum_{j=1}^{n}\left(1-c_{v}^{j}(\mathbf{x} ; \mathcal{S})\right) \frac{\partial w_{v}^{j}(\mathbf{x} ; \mathcal{S})}{\partial x_{2}^{i}}\right]-\gamma \stackrel{!}{=} 0
\end{aligned}
$$

Now assume $E_{\mathcal{S}}\left[\omega_{v}^{1}\right]=1$, implying all $E_{\mathcal{S}}\left[\omega_{v}^{i}\right]=0$ if $i \in\{2,3, \ldots, n\}$, and assume there are no comparative advantages, $E_{\mathcal{S}}\left[\theta_{v}^{i}\left(1-\theta_{v}^{i}\right)\right]=\bar{q} \forall i$ with identical distributions in all issues. Then

$$
\begin{aligned}
\frac{\partial \pi_{1}(\mathbf{x} ; \mathcal{S})}{\partial x_{1}^{1}} & =E_{\mathcal{S}}\left[\frac{\partial c_{v}^{1}(\mathbf{x} ; \mathcal{S})}{\partial x_{1}^{1}}\right]-\gamma \stackrel{!}{=} 0 \\
\frac{\partial \pi_{2}(\mathbf{x} ; \mathcal{S})}{\partial x_{2}^{1}} & =E_{\mathcal{S}}\left[-\frac{\partial c_{v}^{1}(\mathbf{x} ; \mathcal{S})}{\partial x_{2}^{1}}\right]-\gamma \stackrel{!}{=} 0
\end{aligned}
$$


and

$$
\frac{\partial \pi_{k}(\mathbf{x} ; \mathcal{S})}{\partial x_{k}^{i}}=-\gamma<0 \quad \forall k \in\{1,2\} \wedge \forall i \in\{2,3, \ldots, n\}
$$

Hence, in all issues other than 1 no candidate spends anything at all and spending in issue $i$ will be identical for both and given by the condition in (B.3) with $E_{\mathcal{S}}\left[\omega_{v}^{1}\right]=1$ and $E_{\mathcal{S}}\left[\theta_{v}^{i}\left(1-\theta_{v}^{i}\right)\right]=\bar{q}$. If $\gamma$ is sufficiently low, there will be an interior equilibrium in issue 1 with both candidates spending $x_{1}^{1}=x_{2}^{1}=x^{1}>0$ and $x^{i}=0$ if $i>1$. Note that because there are no comparative advantages, both candidates spend the most on there worst issue, because all issues are worst issues. Now assume in issue 1 some interval of voters decrease there evaluation of candidate 1 such that their $\theta_{v}^{1}$ decreases, while all others keep their preferences constant. Then $E_{\mathcal{S}}\left[\theta_{v}^{1}\left(1-\theta_{v}^{1}\right)\right]<\bar{q}$ and issue 1 must be candidate 1's worst issue. Note that as long as issue weights remain unchanged this implies both candidates still spend the same on issue 1 and nothing on all other issues. Hence, candidate 1 spends the most on his single worst issue. Now assume in a last step that $E_{\mathcal{S}}\left[\omega_{v}^{i}\right]=1-\frac{E_{\mathcal{S}}\left[\omega_{v}^{1}\right]}{n-1}$ if $i \in\{2,3, \ldots, n\}$. This implies that all issues other than 1 are identical in the sense that they have identical weights and identical distributions of the $\theta_{v}^{i}$ s. Thus, there exists a completely symmetric equilibrium in those issues. Now assume $E_{\mathcal{S}}\left[\omega_{v}^{1}\right]$ decreases from 1 by a bit and that $\gamma$ is sufficiently low to assure an interior equilibrium. Then, by continuity, there exists some interval $E_{\mathcal{S}}\left[\omega_{v}^{i}\right] \in(0, \bar{w}]$ such that $x_{1}^{1}>x_{1}^{i}>0$, which proves the proposition.

\section{B.4 Proof of Proposition 3}

Proof. As before, to prove the proposition I assume there is a parameter $\zeta$ governing the magnitude of the first derivative of $g^{\prime}(. \mid \zeta)$ in the following way:

$$
\frac{d g^{\prime}(. \mid \zeta)}{d \zeta}<0 \forall \zeta<\bar{\zeta}
$$

and $\frac{d g^{\prime}(\cdot \mid \zeta)}{d \zeta}=0$ if $\zeta \geq \bar{\zeta}$. I assume first $\zeta=\bar{\zeta}$ and show that the result holds. I then argue that a continuity argument proves that the result must also hold for some $\zeta<\bar{\zeta}$.

Assume the following situation. Issues can be ranked according to their importance, where 1 is the ex-ante least important issue and $n$ is the ex-ante most important issue. In particular, 
I assume

$$
\omega^{i}=\frac{2 i}{n(n+1)}
$$

for $i \in\{1,2, \ldots, n\}$. This assumption ensures that $\omega^{1}<\omega^{2}<\cdots<\omega^{n}$ and that $\sum_{i=1}^{n} \omega^{i}=1$. Assume also that we can rank expected ex-ante competence of candidates in the following way:

$$
\theta^{i}=\frac{4 i n-\sqrt{16 i^{2} n^{2}-16 i n(1-i+n)}}{8 i n}
$$

This assumption assures that $\frac{1}{2}=\theta^{1}>\theta^{2}>\cdots>\theta^{n}>0$.

The system of first order conditions in issue $i$ is

$$
\begin{aligned}
\frac{\partial \pi_{1}(\mathbf{x} ; \mathcal{S})}{\partial x_{1}^{i}} & =E_{\mathcal{S}}\left[\frac{\partial c_{v}^{i}(\mathbf{x} ; \mathcal{S})}{\partial x_{1}^{i}} w_{v}^{i}(\mathbf{x} ; \mathcal{S})+\sum_{j=1}^{n} c_{v}^{j}(\mathbf{x} ; \mathcal{S}) \frac{\partial w_{v}^{j}(\mathbf{x} ; \mathcal{S})}{\partial x_{1}^{i}}\right]-\gamma \stackrel{!}{=} 0 \\
\frac{\partial \pi_{2}(\mathbf{x} ; \mathcal{S})}{\partial x_{2}^{i}} & =E_{\mathcal{S}}\left[-\frac{\partial c_{v}^{i}(\mathbf{x} ; \mathcal{S})}{\partial x_{2}^{i}} w_{v}^{i}(\mathbf{x} ; \mathcal{S})+\sum_{j=1}^{n}\left(1-c_{v}^{j}(\mathbf{x} ; \mathcal{S})\right) \frac{\partial w_{v}^{j}(\mathbf{x} ; \mathcal{S})}{\partial x_{2}^{i}}\right]-\gamma \stackrel{!}{=} 0
\end{aligned}
$$

Using $\zeta=\bar{\zeta}$ implies $\frac{\partial w^{i}}{\partial x_{k}^{j}}=0$ for all $i, j, k$, this simplifies to

$$
\begin{aligned}
& \left.\frac{\partial \pi_{1}(\mathbf{x} ; \mathcal{S})}{\partial x_{1}^{i}}\right|_{\zeta=\bar{\zeta}}=E_{\mathcal{S}}\left[\frac{\partial c_{v}^{i}(\mathbf{x} ; \mathcal{S})}{\partial x_{1}^{i}} w_{v}^{i}(\mathbf{x} ; \mathcal{S})\right]-\gamma \stackrel{!}{=} 0 \\
& \left.\frac{\partial \pi_{2}(\mathbf{x} ; \mathcal{S})}{\partial x_{2}^{i}}\right|_{\zeta=\bar{\zeta}}=E_{\mathcal{S}}\left[-\frac{\partial c_{v}^{i}(\mathbf{x} ; \mathcal{S})}{\partial x_{2}^{i}} w_{v}^{i}(\mathbf{x} ; \mathcal{S})\right]-\gamma \stackrel{!}{=} 0
\end{aligned}
$$

Using the specific functional form yields

$$
\begin{aligned}
& \left.\frac{\partial \pi_{1}(\mathbf{x} ; \mathcal{S})}{\partial x_{1}^{i}}\right|_{\zeta=\bar{\zeta}}=E_{\mathcal{S}}\left[\frac{\theta_{v}^{i}\left(1-\theta_{v}^{i}\right) f^{\prime}\left(x_{1}^{i}\right) f\left(x_{2}^{i}\right)}{\left(\theta_{v}^{i} f\left(x_{1}^{i}\right)+\left(1-\theta_{v}^{i}\right) f\left(x_{2}^{i}\right)\right)^{2}}\right] E_{\mathcal{S}}\left[w_{v}^{i}\right]-\gamma \stackrel{!}{=} 0 \\
& \left.\frac{\partial \pi_{2}(\mathbf{x} ; \mathcal{S})}{\partial x_{2}^{i}}\right|_{\zeta=\bar{\zeta}}=E_{\mathcal{S}}\left[\frac{\theta_{v}^{i}\left(1-\theta_{v}^{i}\right) f\left(x_{1}^{i}\right) f^{\prime}\left(x_{2}^{i}\right)}{\left(\theta_{v}^{i} f\left(x_{1}^{i}\right)+\left(1-\theta_{v}^{i}\right) f\left(x_{2}^{i}\right)\right)^{2}}\right] E_{\mathcal{S}}\left[w_{v}^{i}\right]-\gamma \stackrel{!}{=} 0
\end{aligned}
$$

This system of equations has a single solution in which $x_{1}^{i}=x_{2}^{i}=x^{i}$. Using this, we can simply the FOC to

$$
\left.\frac{\partial \pi_{2}(\mathbf{x} ; \mathcal{S})}{\partial x_{2}^{i}}\right|_{\zeta=\bar{\zeta}}=\frac{f^{\prime}\left(x^{i}\right)}{f\left(x^{i}\right)} E_{\mathcal{S}}\left[\theta_{v}^{i}\left(1-\theta_{v}^{i}\right)\right] E_{\mathcal{S}}\left[w_{v}^{i}\right]-\gamma \stackrel{!}{=} 0
$$

Hence, the equilibrium in issue $i$ is completely characterized by

$$
\frac{f^{\prime}\left(x^{i}\right)}{f\left(x^{i}\right)}=\frac{\gamma}{E_{\mathcal{S}}\left[\theta_{v}^{i}\left(1-\theta_{v}^{i}\right)\right] E_{\mathcal{S}}\left[w_{v}^{i}\right]}
$$


Note that the LHS is strictly decreasing in $x^{i}$ iff $f(x)$ is log-concave, which is guaranteed by Assumption 1, implying that spending gets larger as the RHS gets smaller. Now assume $E_{\mathcal{S}}\left[\theta_{v}^{i}\left(1-\theta_{v}^{i}\right)\right]=\frac{n+1-i}{4 i n}$ and $E_{\mathcal{S}}\left[w_{v}^{i}\right]=\frac{2 i}{n(n+1)}$. We then get

$$
\frac{f^{\prime}\left(x^{i}\right)}{f\left(x^{i}\right)}=\frac{2 \gamma n^{2}(1+n)}{n+1-i}
$$

It is clear to see that the RHS is increasing in $i$, and hence $x^{i}$ decreases in $i$. But note that the issues' importance is increasing in $i$. Hence, in that situation the least important issue, issue 1, receives the bulk of attention and the difference in spending between any two issues is strictly positive. To see this note that the difference between any two

$$
E_{\mathcal{S}}\left[\theta_{v}^{i}\left(1-\theta_{v}^{i}\right)\right] E_{\mathcal{S}}\left[w_{v}^{i}\right]-E_{\mathcal{S}}\left[\theta_{v}^{i+1}\left(1-\theta_{v}^{i+1}\right)\right] E_{\mathcal{S}}\left[w_{v}^{i+1}\right]=\frac{1}{2 n^{2}(1+n)}>0
$$

Consequently, the difference in spending between $i$ and $i+1$ must be strictly positive as well for all $i$. This proves the result for the case of $\zeta=\bar{\zeta}$. What happens if we lower $\zeta$ starting at this point? Unfortunately it is not possible to determine efforts precisely. However, we know that the FOCs of the candidates are continuous in all variables and by assumption also in $\zeta$. Hence, marginally lowering $\zeta$ has a marginal impact only on spending and hence we know there must be some interval $\Xi:=[\underline{\zeta}, \bar{\zeta}]$ with positive measure such that the proposition holds also for all $\zeta \in \Xi$. This proves the proposition.

\section{B.5 Proof of Proposition 4}

Proof. This follows immediately from the first order conditions and the assumption of an interior equilibrium. Recall that the system of first-order conditions is as follows:

$$
\begin{aligned}
\frac{\partial \pi_{1}(\mathbf{x} ; s)}{\partial x_{1}^{i}} & =E_{\mathcal{S}}\left[\frac{\partial c_{v}^{i}(\mathbf{x} ; s)}{\partial x_{1}^{i}} w_{v}^{i}(\mathbf{x} ; s)+\sum_{j \neq i}\left(c_{v}^{j}(\mathbf{x} ; s)-c_{v}^{i}(\mathbf{x} ; s)\right) \frac{\partial w_{v}^{j}(\mathbf{x} ; s)}{\partial x_{1}^{i}}\right]-\gamma_{1} \stackrel{!}{=} 0 \\
\frac{\partial \pi_{2}(\mathbf{x} ; s)}{\partial x_{2}^{i}} & =E_{\mathcal{S}}\left[-\frac{\partial c_{v}^{i}(\mathbf{x} ; s)}{\partial x_{2}^{i}} w_{v}^{i}(\mathbf{x} ; s)-\sum_{j \neq i}\left(c_{v}^{j}(\mathbf{x} ; s)-c_{v}^{i}(\mathbf{x} ; s)\right) \frac{\partial w_{v}^{j}(\mathbf{x} ; s)}{\partial x_{1}^{i}}\right]-\gamma_{2} \stackrel{!}{=} 0
\end{aligned}
$$


Subtracting $\frac{\partial \pi_{2}(\mathbf{x} ; s)}{\partial x_{2}^{i}}$ from $\frac{\partial \pi_{1}(\mathbf{x} ; s)}{\partial x_{1}^{i}}$ yields

$$
E_{\mathcal{S}}\left[\left(\frac{\partial c_{v}^{i}(\mathbf{x} ; s)}{\partial x_{1}^{i}}+\frac{\partial c_{v}^{i}(\mathbf{x} ; s)}{\partial x_{2}^{i}}\right) w_{v}^{i}(\mathbf{x} ; s)\right]=-2 E_{\mathcal{S}}\left[\sum_{j \neq i}\left(c_{v}^{j}(\mathbf{x} ; s)-c_{v}^{i}(\mathbf{x} ; s)\right) \frac{\partial w_{v}^{j}(\mathbf{x} ; s)}{\partial x_{1}^{i}}\right]+\Delta
$$

We know that the LHS is positive when 2 spends more and negative when 1 spends more. If nobody spends more on that issue, the LHS is zero. We also know that the RHS takes the opposite sign of $\sigma^{i}$ when $\Delta=0$. The proposition follows.

\section{References}

Amorós, P., And M. Puy (2013): "Issue convergence or issue divergence in a political campaign?," Public Choice, 155, 355-371.

Aragonès, E., M. Castanheira, and M. Giani (2014): "Electoral Competition through Issue Selection," American Journal of Political Science, pp. n/a-n/a.

BAgwell, K. (2007): "The Economic Analysis of Advertising," in Handbook of Industrial Organization, ed. by M. Armstrong, and R. Porter, vol. 3, pp. 1701-1844. Elsevier.

Bélanger, E., And B. M. Meguid (2008): "Issue salience, issue ownership, and issue-based vote choice," Electoral Studies, 27(3), 477-491.

Bühler, S., And D. Halbheer (2011): "Selling when Brand Image Matters," Journal of Institutional and Theoretical Economics, 167(1), 102-118.

(2012): "Persuading consumers with social attitudes," Journal of Economic Behavior E Organization, 84(1), 439-450.

Bornstein, R. F. (1989): "Exposure and affect: Overview and meta-analysis of research, 1968-1987," Psychological Bulletin, 106, 265-289.

Chowdhury, S. M., D. Kovenock, and R. M. Sheremeta (2013): "An experimental investigation of Colonel Blotto games," Economic Theory, 52(3), 833-861.

Costinot, A. (2009): "On the origins of comparative advantage," Journal of International Economics, 77(2), 255-264.

Damore, D. F. (2004): "The Dynamics of Issue Ownership in Presidential Campaigns," Political Research Quarterly, 57(3), 391-397.

$71-97$.

(2005): "Issue Convergence in Presidential Campaigns," Political Behavior, 27(1),

Druckman, J. N., L. R. Jacobs, and E. Ostermeier (2004): "Candidate Strategies to Prime Issues and Image," Journal of Politics, 66(4), 1180-1202.

Erikson, R. S., And T. R. Palfrey (2000): "Equilibria In Campaign Spending Games: Theory And Data," American Political Science Review, 94, 595-609.

FudenberG, D., and J. Tirole (1991): Game Theory. The Mit Press. 
Garfinkel, M. R., S. Skaperdas, and C. Syropoulos (2009): "International Trade and Transnational Insecurity: How Comparative Advantage and Power are Jointly Determined," Discussion paper.

Green, J., And S. B. Hobolt (2008): "Owning the issue agenda: Party strategies and vote choices in British elections," Electoral Studies, 27(3), 460 - 476.

Groseclose, T. (2001): "A Model of Candidate Location When One Candidate Has a Valence Advantage," American Journal of Political Science, 45(4), pp. 862-886.

Harmon-Jones, E., and J. J. B. Allen (2001): "The Role of Affect in the Mere Exposure Effect: Evidence from Psychophysiological and Individual Differences Approaches," Personality and Social Psychology Bulletin, 27(7), 889-898.

Hogg, M. A., And G. M. Vaughan (2008): Social Psychology. Pearson Education Limited, 5 edn.

IARyczower, M., and A. Mattozzi (2011): "The Pro-Competitive Effect of Campaign Limits in Non-Majoritarian Elections," Economic Theory, pp. 1-29, 10.1007/s00199-011-0613-y.

(2013): "On the Nature of Competition in Alternative Electoral Systems," The Journal of Politics, 75, 743-756.

Iyengar, S., And D. R. Kinder (1987): News That Matters: Television and American Opinion. University of Chicago Press.

Jensen, T. (2012): "Elections, Private Information, and State-Dependent Candidate Quality," Discussion paper.

Johnson, J. P., and D. P. Myatt (2006): "On the Simple Economics of Advertising, Marketing, and Product Design," American Economic Review, 96(3), 756-784.

Jones, J. P. (1999): "What Does Effective Frequency Mean Today?" in The Advertising Business: Operations, Creativity, Media Planning, Integrated Communications, ed. by J. P. Jones, chap. 28, pp. 285-299. SAGE Publications.

Kamada, Y., And F. KoJima (2013): "The equivalence between costly and probabilistic voting models," Games and Economic Behavior, 80(0), 179-185.

Kaplan, N., D. K. Park, and T. N. Ridout (2006): "Dialogue in American Political Campaigns? An Examination of Issue Convergence in Candidate Television Advertising," American Journal of Political Science, 50(3), 724-736.

Klumpp, T., And M. K. Polborn (2006): "Primaries and the New Hampshire Effect," Journal of Public Economics, 90(6-7), 1073-1114.

Kovenock, D., and B. Roberson (2010): "Conflicts with Multiple Battlefields," CESifo Working Paper Series 3165, CESifo Group Munich.

(2012): "Coalitional Colonel Blotto Games with Application to the Economics of Alliances," Journal of Public Economic Theory, 14(4), 653-676.

Krasa, S., And M. Polborn (2010a): "The binary policy model," Journal of Economic Theory, 145(2), 661-688.

(2010b): "Competition between Specialized Candidates," American Political Science Review, 104(04), 745-765. 
- (2012): "Political competition between differentiated candidates," Games and Economic Behavior, 76(1), 249-271.

Lancaster, K. J. (1966): "A New Approach to Consumer Theory," Journal of Political Economy, $74,132$.

LindBeck, A., And J. W. Weibull (1987): "Balanced-budget redistribution as the outcome of political competition," Public Choice, 52(3), 273-297.

Moon, W. G., D. M. Mackie, and T. Garciamarques (2009): "The impact of repetitioninduced familiarity on agreement with weak and strong arguments," Journal of Personality and Social Psychology, 96(1), 32-44.

Mueller, D. C., and T. Stratmann (1994): "Informative and Persuasive Campaigning," Public Choice, 81(1-2), 55-77.

Petrocik, J. (1996): "Issue Ownership in Presidential Elections, with a 1980 Case Study," American Journal of Political Science, 40(3), 825-50.

Petrocik, J. R., W. L. Benoit, and G. J. Hansen (2003): "Issue Ownership and Presidential Campaigning, 1952-2000," Political Science Quarterly, 118(4), pp. 599-626.

Powell, R. (2007): "Allocating Defensive Resources with Private Information about Vulnerability," American Political Science Review, 101(04), 799-809.

Riker, W. H. (1996): The Strategy of Rhetoric. Yale University Press.

Roberson, B. (2006): "The Colonel Blotto game," Economic Theory, 29(1), 1-24-24.

Serenko, A., And N. Bontis (2011): "What's familiar is excellent: The impact of exposure effect on perceived journal quality," Journal of Informetrics, 5(1), 219-223.

Severin, W., and J. Tankard (1997): Communication Theories. New York: Hastings House.

Shubik, M., and R. J. Weber (1981): "Systems Defense Games: Colonel Blotto, Command and Control," Naval Research Logistics Quarterly, 28(2), 281-287.

Sigelman, L., And E. H. Buell (2004): "Avoidance or Engagement? Issue Convergence in U.S. Presidential Campaigns, 1960-2000," American Journal of Political Science, 48(4), 650-661.

Simon, A. (2002): The Winning Message: Candidate Behavior, Campaign Discourse, and Democracy. Cambidge University Press.

Skaperdas, S., and B. Grofman (1995): "Modeling Negative Campaigning," The American Political Science Review, 89(1), 49-61.

Skaperdas, S., And S. Vaidya (2012): "Persuasion as a contest," Economic Theory, 51(2), 465-486.

Smith, E. R., and D. M. Mackie (2007): Social Psychology. Psychology Press, 3 edn.

SNyder, J. M. (1989): "Election Goals and the Allocation of Campaign Resources," Econometrica, 57(3), pp. 637-660.

Stromberg, D. (2008): "How the Electoral College Influences Campaigns and Policy: The Probability of Being Florida," American Economic Review, 98(3), 769-807. 
Tom, G., C. Nelson, T. Srzentic, and R. King (2007): "Mere exposure and the endowment effect on consumer decision making," The Journal of Psychology, 141(2), 117-125.

Weaver, D. H. (2007): "Thoughts on Agenda Setting, Framing, and Priming," Journal of Communication, 57(1), 142-147.

Willnat, L. (1997): "Agenda Setting and Priming: Conceptual Links and Differences," in Communication and Democracy: Exploring the Intellectual Frontiers in Agenda-Setting Theory, p. 51-66. Routledge.

ZaJonc, R. B. (1968): "Attitudinal Effects of Mere Exposure," Journal of Personality and Social Psychology, 9(2P2), 1-\&.

(1980): "Feeling and Thinking - Preferences Need No Inferences," American Psychologist, 35(2), 151-175.

(2001): "Mere exposure: A gateway to the subliminal," Current Directions in Psychological Science, 10(6), 224-228. 